\title{
Therapeutic roles of mesenchymal stem cell-derived extracellular vesicles in cancer
}

\author{
Zhijie Weng ${ }^{1 \dagger}$, Bowen Zhang ${ }^{2 \dagger}$, Chenzhou Wu ${ }^{1}$, Fanyuan $\mathrm{Yu}^{3}$, Bo Han ${ }^{2}$, Bo Li ${ }^{4^{*}}$ and Longjiang $\mathrm{Li}^{i^{*}}$
}

\begin{abstract}
Extracellular vesicles (EVs) are cell-derived membrane structures enclosing proteins, lipids, RNAs, metabolites, growth factors, and cytokines. EVs have emerged as essential intercellular communication regulators in multiple physiological and pathological processes. Previous studies revealed that mesenchymal stem cells (MSCs) could either support or suppress tumor progression in different cancers by paracrine signaling via MSC-derived EVs. Evidence suggested that MSC-derived EVs could mimic their parental cells, possessing pro-tumor and anti-tumor effects, and inherent tumor tropism. Therefore, MSC-derived EVs can be a cell-free cancer treatment alternative. This review discusses different insights regarding MSC-derived EVs' roles in cancer treatment and summarizes bioengineered MSC-derived EVs' applications as safe and versatile anti-tumor agent delivery platforms. Meanwhile, current hurdles of moving MSC-derived EVs from bench to bedside are also discussed.
\end{abstract}

Keywords: Mesenchymal stem cell, Extracellular vesicle, Exosome, Cancer therapy, Drug delivery

\section{Background}

Extracellular vesicles (EVs) are nano-sized bilayerenclosed membrane structures containing proteins, lipids, RNAs, metabolites, growth factors, and cytokines, acting as versatile transporters between cells [1]. The EVs were first discovered by Peter Wolf in 1967 and were initially considered as "platelet dust" [2]. During the past 50 years, increasing information on EVs has become available. All cells can secrete EVs during normal and pathological processes [3]. EVs can participate in different diseases, especially cancers. EVs have been shown to transfer biomolecules between tumor cells, stromal cells, fibroblasts, endothelial cells, and immune cells,

\footnotetext{
*Correspondence: libo.scu@foxmail.com; lilongjiang63@163.com ${ }^{\dagger}$ Zhijie Weng and Bowen Zhang contributed equally to the work and should be regarded as co-first authors

${ }^{1}$ State Key Laboratory of Oral Diseases, National Clinical Research Center for Oral Diseases, Department of Head and Neck Oncology, West China Hospital of Stomatology, Sichuan University, Chengdu, China

${ }^{4}$ State Key Laboratory of Oral Diseases, National Clinical Research Center for Oral Diseases, Department of Orthodontics, West China Hospital of Stomatology, Sichuan University, Chengdu, China

Full list of author information is available at the end of the article
}

facilitating communication throughout the tumor microenvironment as paracrine mediators. Therefore, EVs are involved in cancer pathogenesis, progression, metastasis, and immunomodulation. The correlation between oncological states and EVs' existence in biological fluids favors their utility as an effective diagnostic tool in minimally invasive liquid biopsies by tumor biomarkers identification [4].

The more common application of EVs is based on their transport properties in delivering functional cargoes to targeted cells, rendering them attractive as drug delivery vehicles. Some native EVs harboring endogenous anti-tumor biomolecules can be exploited as therapeutic agents. Moreover, bioengineered EVs with additional desired cargoes and targeting specificity are holding brighter prospects in cancer therapy. Meanwhile, in contrast to other commonly applied drug delivery vehicles (e.g., liposomes), bioengineered EVs possess their merit due to their intrinsic targeting capabilities, low immunogenicity, high modification flexibility, as well as biological barrier permeability [5].

Since EVs are endogenous cellular products, they have an absolute requirement for parental cell sources to

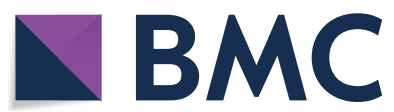

(c) The Author(s) 2021. Open Access This article is licensed under a Creative Commons Attribution 4.0 International License, which permits use, sharing, adaptation, distribution and reproduction in any medium or format, as long as you give appropriate credit to the original author(s) and the source, provide a link to the Creative Commons licence, and indicate if changes were made. The images or other third party material in this article are included in the article's Creative Commons licence, unless indicated otherwise in a credit line to the material. If material is not included in the article's Creative Commons licence and your intended use is not permitted by statutory regulation or exceeds the permitted use, you will need to obtain permission directly from the copyright holder. To view a copy of this licence, visit http://creativecommons.org/licenses/by/4.0/. The Creative Commons Public Domain Dedication waiver (http://creativeco mmons.org/publicdomain/zero/1.0/) applies to the data made available in this article, unless otherwise stated in a credit line to the data. 
obtain prolific production. Nowadays, EVs for therapeutic applications are typically derived from mesenchymal stem cells (MSCs), a cell type well characterized for EV mass production [6]. MSCs, also known as multipotent mesenchymal stromal cells, are multipotent adult stem cells that can be isolated from bone marrow $[7,8]$, umbilical cord tissue [9, 10], placental tissue [11, 12], adipose tissue $[13,14]$, and dental tissue $[15,16]$. Due to their potential to differentiate into mesoderm- and nonmesoderm-derived tissues, in vitro and in vivo [17], these cells can have a regenerative ability and are preferred for treating various tissue injuries. Besides, MSCs have been found to actively migrate toward inflammatory sites and to modulate immune responses [18]. Nevertheless, recently more attention has been focused on MSCs' therapeutic roles in cancer. MSCs can preferentially migrate toward tumors and be incorporated into tumor stroma [19-22]. Now it is well established that MSCs can regulate the tumor cell fate in a paracrine manner rather than a cellular one. MSC-derived EVs are major contributors among such paracrine effectors [23]. Moreover, MSCderived EVs possess significant bioengineering potential as a guided anti-tumor drug delivery platform due to their strong migrating tropism toward tumor sites [2426]. Figure 1 summarizes the key steps in the process of MSC-derived EVs' therapeutic applications.

In this article, we first review EVs' biogenesis and their purification and characterization technologies. Then, we summarize current findings regarding MSC-derived EVs' physiological functions in cancers, from participation in tumor angiogenesis, proliferation inhibition and apoptosis promotion, to growth and metastasis facilitation, dormancy and chemoresistance induction. Next, we assemble the latest advances in drug loading and manufacturing of EV therapeutics, with particular emphasis on cargo and surface engineering techniques. MSC-derived EVs' advantages as ideal drug delivery vehicles are also discussed by comparison with other nanocarriers and EVs derived from other sources. Then, based on the previous understanding, we detail the bioengineered MSCderived EVs' applications as a drug delivery system in cancer therapy. Finally, we discuss future challenges and directions regarding MSC-derived EV-based anti-cancer applications.

\section{Biological characteristics of extracellular vesicles Biogenesis}

EVs are broadly categorized into two major classes: ectosomes and exosomes. Ectosomes $(50-1000 \mathrm{~nm}$ in diameter) are vesicles released through plasma membrane outward budding and include microvesicles, microparticles, and large vesicles. Exosomes (40-160 nm in diameter) are endosomal vesicles formed through iterative plasma membrane invagination. After the early formation of cup-shaped structures, early-sorting endosomes (ESEs) and late-sorting endosomes (LSEs), multivesicular bodies (MVBs) are eventually generated, containing intraluminal vesicles (ILVs). Upon MVBs fusion with the plasma membrane, ILVs are released by exocytosis into the extracellular environment as exosomes. Some MVBs are degraded by lysosomes or autophagosomes fusion [4].

\section{Purification}

Different technologies are currently used for EV purification, including differential ultracentrifugation, density gradient ultracentrifugation, size exclusion chromatography, tangential flow filtration, and affinity capture [27].

Until now, differential ultracentrifugation-an initial, well-established, and reliable method-is still the most widely adopted approach due to its simplistic protocol and relatively high yield [28]. By increasing centrifugation speed and/or time in a stepwise manner, it can separate particles with different sedimentation rates, then remove undesired components during each centrifugation. However, this approach cannot distinguish particles with overlapping ranges, such as exosomes and microvesicles. Density gradient ultracentrifugation, size exclusion chromatography, and filtration present similar problems, depending on particle density or size for separation. Different from these physical-based isolation methods, affinity capture can separate EVs with high-purity but with low-yield via EV surface markers interaction with the capture molecules attached to different carriers (e.g., magnetic beads) [29].

The International Society for Extracellular Vesicles (ISEV) has proposed detailed guidance for these isolation methods [30]. However, none achieved the absolute purification, that is, completely isolating EVs from other biological products. Each method has advantages and disadvantages, and their combinations might be recommended for maximum EV enrichment. Based on some comparative studies [31-35], we have summarized the characteristics of different $\mathrm{EV}$ isolation methods in Table 1.

\section{Characterization}

It is essential to thoroughly characterize EVs according to ISEV's minimal criteria report to validate the isolation method. A comprehensive EV characterization embraces general and single vesicle characterization.

The general characterization usually focuses on some protein markers using Western Blot or ELISA. The ISEV suggests the characterization of at least three positive and one negative EV protein marker. Positive protein markers should include at least one transmembrane/lipid-bound 


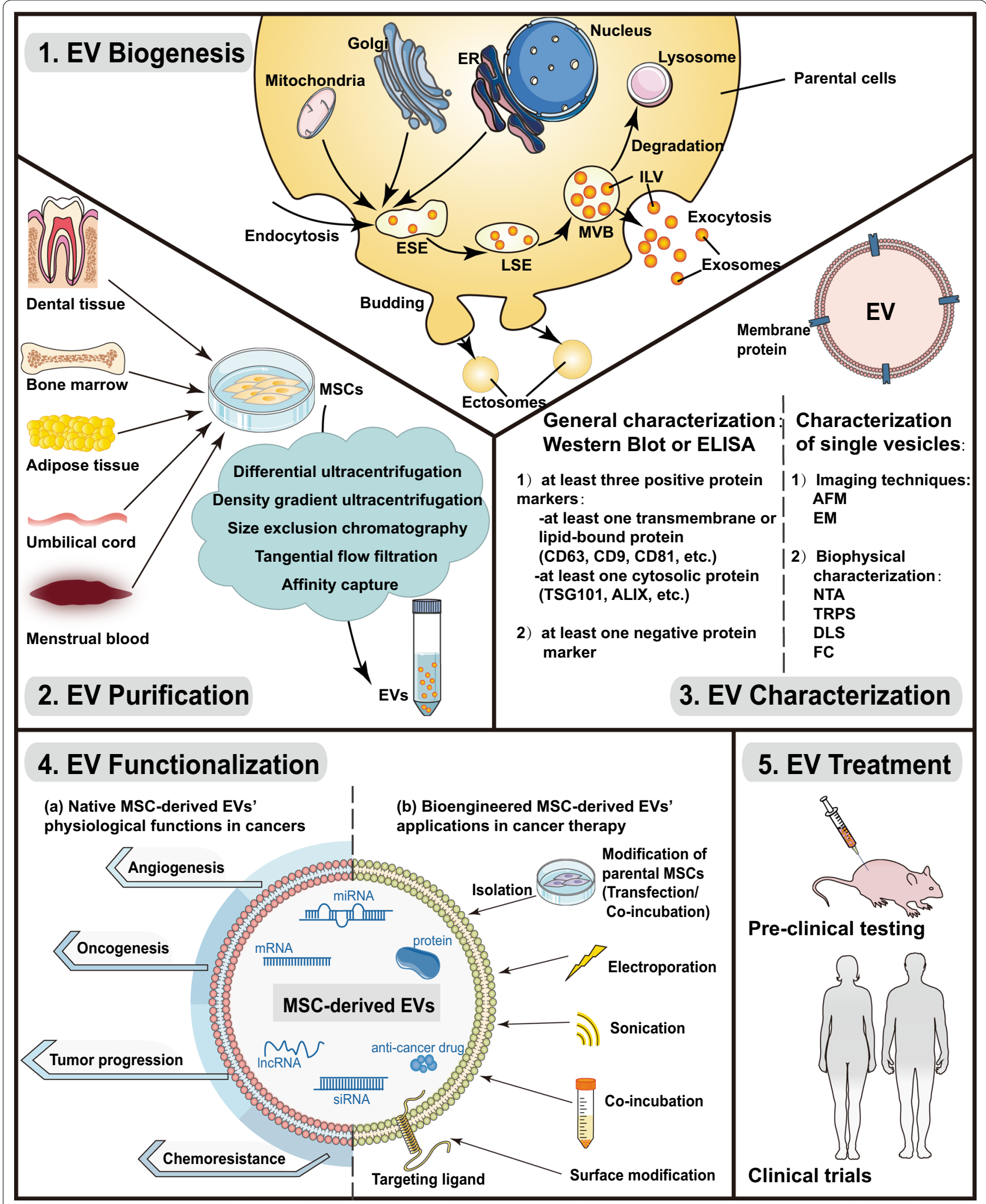

Fig. 1 Key steps in the process of MSC-derived EVs' therapeutic applications. AFM atomic force microscopy, DLS dynamic light scattering, EM electron microscopy, ER endoplasmic reticulum, ESE early-sorting endosome, FC flow cytometry, ILV intraluminal vesicle, LSE late-sorting endosome, MVB multivesicular body, NTA nanoparticle tracking analysis, TRPS tunable resistance pulse sensing 
Table 1 Overview of EV isolation methods

\begin{tabular}{|c|c|c|c|c|}
\hline Isolation method & Principle & Advantages & Disadvantages & References \\
\hline Differential ultracentrifugation & Based on differential centrifugation & $\begin{array}{l}\text { Most commonly used } \\
\text { and well established } \\
\text { Simple } \\
\text { Economical } \\
\text { Relatively high yield }\end{array}$ & $\begin{array}{l}\text { Low purity } \\
\text { Low upscale potential }\end{array}$ & {$[31,34]$} \\
\hline Density gradient ultracentrifugation & Based on density gradient of solutions & $\begin{array}{l}\text { Relatively high purity } \\
\text { Maintain EV integrity }\end{array}$ & $\begin{array}{l}\text { Time-consuming } \\
\text { Lower yield } \\
\text { Low upscale potential }\end{array}$ & {$[31,34]$} \\
\hline Size exclusion chromatography & Based on particle size & $\begin{array}{l}\text { Economical } \\
\text { Relatively high purity } \\
\text { Maintain EV integrity } \\
\text { High upscale potential }\end{array}$ & $\begin{array}{l}\text { Time-consuming } \\
\text { Lower yield } \\
\text { Contamination }\end{array}$ & {$[32]$} \\
\hline Tangential flow filtration & Based on particle size & $\begin{array}{l}\text { High yield } \\
\text { High purity } \\
\text { High time-efficiency } \\
\text { High upscale potential }\end{array}$ & $\begin{array}{l}\text { Complicated equipment } \\
\text { Difficult operation } \\
\text { Limited understanding }\end{array}$ & {$[33,35]$} \\
\hline Affinity capture & $\begin{array}{l}\text { Based on interaction of capture mol- } \\
\text { ecule with EV antigen }\end{array}$ & $\begin{array}{l}\text { High purity } \\
\text { Specific separation }\end{array}$ & $\begin{array}{l}\text { Low yield } \\
\text { Costly } \\
\text { Separate targeted proteins only }\end{array}$ & {$[31,34]$} \\
\hline
\end{tabular}

protein (e.g., CD63, CD9, CD81) and one cytosolic protein (e.g., TSG101, ALIX).

Single vesicle characterization requires imaging techniques and biophysical characterization. Atomic force microscopy (AFM) and electron microscopy (EM), including transmission electron microscopy (TEM) and scanning electron microscopy (SEM), are the only imaging techniques able to capture high-resolution EV morphology images. Immunogold EM is commonly used to stain specific EV markers. Biophysical characterization involves nanoparticle tracking analysis (NTA), tunable resistance pulse sensing (TRPS), dynamic light scattering (DLS), and flow cytometry (FC), for example [30].

However, detailed characterization of EV subpopulations and molecular composition of each EV type remains unavailable [36].

\section{Physiological functions of MSC-derived EVs in cancers \\ Participation in tumor angiogenesis}

Discussions about MSC-derived EVs' functions in cancer emerged since Zhu et al. [37] firstly reported that exosomes secreted by MSCs could promote tumor growth in vivo, similarly to MSCs. They found that exosomes derived from human bone marrow mesenchymal stem cells (hBMSCs) favored tumor growth in xenograft mice models of gastric and colon cancers. However, the exosomes did not present similar effects on tumor cells in vitro. On the other hand, angiogenesis-related molecular signaling pathway activation was found in vivo and in vitro with increased VEGF and CXCR4 mRNA levels, which coincided with the higher vascular density observed in tumor tissues in vivo. Finally, they demonstrated that hBMSC-derived exosomes could increase VEGF and CXCR4 expression in tumor cells by ERK1/2 and p38 MAPK pathways activation, leading to enhanced angiogenesis, thus promoting tumor growth in vivo.

However, opposite effects have been discovered in breast cancer cells. Lee et al. [38] reported that hBMSCderived exosomes could inhibit angiogenesis and tumor progression in vitro and in vivo by transferring miR-16 into tumor cells, which could target VEGF and reduce its expression in breast cancer cells. They were the first to describe tumor microenvironment reprogramming conducted by miRNAs in MSC-derived exosomes. This view was supported by Pakravan et al. [39], who pointed out that miR-100 was enriched in hBMSC-derived exosomes and suppressed angiogenesis in vitro through VEGF downregulation in breast cancer cells. Further, they demonstrated that miR-100 exosomal transfer mediated VEGF expression via the mTOR/HIF- $1 \alpha$ signaling axis.

Besides BMSCs, human menstrual stem cells (MenSCs) isolated from menstrual fluids also have great potential as angiogenic regulators. It is easy to understand based on common sense that physiological angiogenesis occurs during the female menstrual cycle. Currently, the exploration of MenSCs' therapeutic mechanisms is only emerging, especially in the cancer context. AlcayagaMiranda et al. found that MenSC-derived exosomes decreased angiogenesis in prostate adenocarcinoma in vivo and in vitro, inhibiting reactive oxygen species (ROS) pathway, therefore downregulating the secretion of pro-angiogenic factors (e.g. VEGF, FGF) and NF- $\mathrm{KB}$ transcription factor [40]. Besides, by altering prostate 
adenocarcinoma cell culturing conditions, they successfully proved that the observed anti-angiogenic effect was mediated by exosomes rather than direct intercellular contact with MenSCs or other secretomes. Also, tumor angiogenesis and growth inhibition was found in the hamster buccal pouch carcinoma model treated with MenSC-derived exosomes [41]. In this paper, tumor cells and endothelial cells internalized MenSC-derived exosomes and had lower VEGF expression under exosomal modulation, resulting in tumor angiogenesis and growth inhibition in vivo.

\section{Proliferation inhibition and apoptosis promotion}

Despite MSC-derived EVs' indirect pathway to modulate tumor angiogenesis that influences tumor growth in turn, many researchers tried to clarify whether MSC-derived EVs can directly affect tumor cell proliferation and apoptosis in cancer progression. In the beginning, researchers used different cancer cell lines and mice xenograft models to verify MSC-derived EVs' modulatory roles in the cancer cell cycle, proliferation, and apoptosis. EVs from hBMSCs have been reported to activate cell cycle negative regulators, leading to apoptosis or necrosis and antiproliferation of tumor cells in hepatocellular carcinoma, ovarian cancer, and Kaposi's sarcoma [42]. Similarly, the anti-proliferative and pro-apoptotic effects of EVs derived from human umbilical cord mesenchymal stem cells (hUCMSCs) were detected in bladder carcinoma. These effects were related to restrained AKT protein kinase phosphorylation and increased Caspase 3 cleavage [43].

Next, continued concern has been raised about which factor delivered by MSC-derived EVs into target tumor cells were dominant in cancer progression. Reza et al. [44] observed that incorporating human adipose mesenchymal stem cell (hAMSC)-derived exosomes attenuated ovarian cancer cell proliferation and induced apoptosis. Next, they treated ovarian cancer cells with proteasedigested exosomes or RNase-digested exosomes to explore whether exosomal protein or RNA was responsible for the observed effects. No significant differences between protease-digested and fresh exosomes were detected, while the RNase-digested exosomes had no anti-proliferation effect in ovarian cancer cells. After subsequent verifications, they concluded that oncogene-related miRNAs in hAMSC-derived exosomes were responsible for the anti-tumor activities observed. The miRNAs led to enhanced mitochondria-mediated apoptosis in ovarian cancer cells by pro-apoptotic molecules upregulation and anti-apoptotic proteins downregulation.

To date, researchers have gained a better understanding of miRNAs in different MSC-derived EVs in various cancer types. For instance, miRNA-145 upregulation in hAMSC-derived exosomes had a suppressive role in prostate cancer progression and induced apoptosis via the Caspase-3/7 pathway [45]. Another miRNA, let-7i, could be transferred from hBMSC-derived EVs into lung cancer cells to abolish tumor cell proliferation via the KDM3A/DCLK1/FXYD3 axis [46]. However, further extensive investigations are still required to determine the underlying mechanism of exosomal miRNAs or other unknown cargoes in cancer progression.

\section{Growth and metastasis facilitation}

On the other hand, MSC-derived EVs can also exhibit pro-proliferative effects on cancer cells, different from their described roles so far. For example, hBMSC-derived EVs promoted proliferation, migration, and tumorigenesis in nasopharyngeal carcinoma [47] and osteosarcoma [48]. HUCMSC-derived EVs had a similar effect in renal cancer [49], lung cancer [50, 51], and breast cancer [52]. It is not surprising that miRNAs contained in EVs have also been verified as important contributors to such modulations. For example, transferred miR-410 from hUCMSC-derived EVs favored lung adenocarcinoma growth by targeted inhibition of PTEN, which was involved in tumor cell proliferation and apoptosis [50]. Another miRNA, miR-130b-3p, was also enriched in hUCMSC-derived EVs and transferred into lung cancer cells, playing an oncogenic role via the FOXO3/NFE2L2/ TXNRD1 axis [51]. Likewise, overexpressed miR-21-5p, delivered by hypoxia pre-challenged hBMSC-derived EVs, exerted pro-proliferative and pro-metastatic effects by abrogating apoptosis and inducing macrophage M2 polarization in lung cancer, with low protein expression of several pro-apoptotic genes (e.g., PTEN, PDCD4, and RECK)[53]. Also, lower-expressed miR-15a in hBMSCderived exosomes from multiple myeloma patients was identified as a key mediator in pro-tumor activities [54].

Additionally, lncRNAs, mRNAs, and proteins encapsulated in EVs received increasing attention. Du et al. [49] reported that hUCMSC-derived EVs promoted tumor growth and metastasis in renal cancer via AKT and ERK1/2 signaling pathways activation. The effect was derived from hepatocyte growth factor (HGF) synthesis induction in the presence of human HGF mRNA transferred by the EVs. Zhao et al. [48] demonstrated that the lncRNA PVT1 packed in hBMSC-derived exosomes upregulated the oncogenic protein ERG by restraining ERG degradation and ubiquitination, as well as sponging miR183-5p. Finally, it brought about enhanced growth and metastasis in osteosarcoma. Regarding exosomal proteins, Mao et al.[55] reported that E3 ubiquitin-protein ligase UBR2 was enriched in p53 deficient mouse BMSCderived exosomes. UBR2 expression was also increased 
in gastric cancer cells treated with the exosomes, enhancing tumor growth and metastasis via the $\mathrm{Wnt} / \beta$-catenin pathway. Overall, these results suggested that exosomal miRNAs, lncRNAs, mRNAs, and proteins can be transported into target cells and play specific roles.

Particularly, vital links between epithelial-mesenchymal transition (EMT) and tumor progression received growing recognition. EMT is a cellular process in which cells switch from an epithelial phenotype to a mesenchymal one, reducing cell-to-cell adhesion and elevating migratory capacity [56]. Several studies have shown that the MSC-derived EVs' pro-metastatic effects in tumor cells are related to EMT induction. Shi et al. [47] discovered that hBMSC-derived exosomes enhanced FGF19FGFR4 dependent ERK signaling cascade activation and induced EMT of nasopharyngeal carcinoma cells. They were incubated with the exosomes, leading to enhanced tumor growth and metastasis. Similarly, Zhou et al. [52] reported that hUCMSC-derived EVs facilitated tumor progression and metastasis in breast cancer by EMT induction via ERK pathway upregulation.

\section{Dormancy and chemoresistance induction}

Tumor dormancy has been a research hotspot in metastatic cancer progression. It refers to tumor cells' ability to remain in small amounts and undetectable at the metastatic site after primary tumor resection. The dormancy is associated with chemoresistance, prolonged asymptomatic residual disease, and cancer recurrence [57]. Breast cancer is one of the best-known tumor dormancy cases. Disseminated breast cancer cells can migrate to the bone marrow, then induce prolonged dormancy within the mesenchymal stem cell niche, down-regulating cell proliferation and invasion, as well as up-regulating cell adhesion [58]. Questions have been raised about the dormancy initiation in the bone marrow microenvironment. Evidence suggested that the resident MSCs play a key role [59]. Therefore, researchers have focused on involved cellular mechanism between MSCs and tumor dormancy. Ono et al. [60] demonstrated that exosomes secreted from hBMSCs transferred miR-23b into metastatic breast cancer cells, inducing tumor dormancy by inhibiting its target oncogene MARCKS. This finding was consistent with Casson et al. [61]. Casson et al. reported that metastatic breast cancer cells treated with hBMSCderived EVs were induced to undergo a mesenchymalepithelial transition (MET) and maintained a dormant state, shown as migration inhibition and cell adhesion promotion. The two studies showed that the dormancy kept tumor cells in a cycling quiescent state, thus helping them hide from chemotherapy and gain chemoresistance.

Similarly, hUCMSC-derived exosomes enforced dormancy and protected tumor cells against conventional treatments by transferring exosomal miRNAs in metastatic breast cancer [62]. Apart from breast cancer, gastric cancer's chemoresistance was also enhanced by hUCMSC-derived exosomes [63]. In this case, exosomal proteins, rather than exosomal miRNAs, conferred the drug resistance by CaM-Ks/Raf/MEK/ERK pathway activation.

In conclusion, EVs derived from different MSCs have diverse effects on specific tumors. The studies mentioned in this section are summarized in Table 2 and Fig. 2. These conflicting experimental results could be associated with the heterogeneity of MSCs, the complexity of tumor microenvironment, the diversity of malignancies' origin, and the difference of experimental conditions. Multiple mechanisms and cargoes of the EVs may be involved in tumor progression modulation. There is still ample room for further progress to articulate these signaling interactions.

\section{Current technologies for drug loading and manufacturing of EV therapeutics}

Compared with native EVs, bioengineered EVs exhibit a higher therapeutic potential as delivery vehicles because they can transfer desired cargoes and confer enhanced targeting specificity. So far, two major strategies are applied to maximize therapeutic efficacy of EVs: cargo engineering and surface engineering (summarized in Fig. 3).

\section{Cargo engineering}

EVs can encapsulate different therapeutic agents, including drugs, proteins, and nucleic acids. Cargo loading approaches are generally divided into two categories: preloading (before EV isolation) and post-loading (after EV isolation).

\section{Pre-loading}

By modifications of parental cells, therapeutic cargoes can be endogenously packaged into EVs during the biogenesis process before EV isolation. This can be performed by genetic manipulation of parental cells [64]. By cell transfection, parental cells can overexpress therapeutic miRNAs, siRNAs, mRNAs, proteins, and peptides, which will subsequently be encapsulated into EVs. Another approach is directly incubating drugs with parental cells, enabling the production of drug-containing EVs.

Pre-loading strategies provide relatively simple and stable production of EVs enclosed with desired active components, besides maintaining EV membrane integrity. 
Table 2 Effects of native MSC-derived EVs on different types of cancer

\begin{tabular}{|c|c|c|c|c|c|c|}
\hline EV source & Cancer & Method & Key cargo & Effect & $\begin{array}{l}\text { Proposed } \\
\text { mechanism }\end{array}$ & Reference \\
\hline hBMSCs & $\begin{array}{l}\text { Gastric cancer; colon } \\
\text { cancer }\end{array}$ & In vitro and in vivo & N/A & $\begin{array}{l}\text { Angiogenesis } \uparrow \\
\text { Cell proliferation } \uparrow\end{array}$ & $\begin{array}{l}\text { Activation of ERK } 1 / 2 \\
\text { and p38 MAPK } \\
\text { pathways }\end{array}$ & [37] \\
\hline hBMSCs & Mouse breast cancer & In vitro and in vivo & miR-16 & $\begin{array}{l}\text { Angiogenesis } \downarrow \\
\text { Tumor progression } \downarrow\end{array}$ & VEGF $\downarrow$ & [38] \\
\hline hBMSCs & Breast carcinoma & In vitro & miR-100 & $\begin{array}{l}\text { Angiogenesis } \downarrow \\
\text { Endothelial cell prolif- } \\
\text { eration } \downarrow \\
\text { Migration } \downarrow\end{array}$ & $\begin{array}{l}\text { mTOR/HIF-1 a/VEGF } \\
\text { signaling axis }\end{array}$ & [39] \\
\hline hMenSCs & $\begin{array}{l}\text { Prostate adenocarci- } \\
\text { noma }\end{array}$ & In vitro and in vivo & $\mathrm{N} / \mathrm{A}$ & $\begin{array}{l}\text { Angiogenesis } \downarrow \\
\text { Tumor progression } \downarrow\end{array}$ & $\begin{array}{l}\text { ROS } \downarrow \\
\text { VEGF } \downarrow\end{array}$ & {$[40]$} \\
\hline hMenSCs & $\begin{array}{l}\text { Hamster buccal } \\
\text { pouch carcinoma }\end{array}$ & In vitro and in vivo & N/A & $\begin{array}{l}\text { Endothelial cell apop- } \\
\quad \text { tosis } \uparrow \\
\text { Tumor progression } \downarrow\end{array}$ & VEGF $\downarrow$ & [41] \\
\hline hBMSCs & $\begin{array}{l}\text { Hepatocellular } \\
\text { carcinoma; ovarian } \\
\text { cancer; Kaposi's } \\
\text { sarcoma }\end{array}$ & In vitro and in vivo & $\mathrm{N} / \mathrm{A}$ & Tumor progression $\downarrow$ & $\begin{array}{l}\text { Activation of negative } \\
\text { regulators of cell } \\
\text { cycle }\end{array}$ & {$[42]$} \\
\hline hUCMSCs & Bladder carcinoma & In vitro and in vivo & N/A & $\begin{array}{l}\text { Proliferation } \downarrow \\
\text { Apoptosis } \uparrow\end{array}$ & $\begin{array}{l}\text { Phosphorylation of } \\
\text { Akt protein kinase } \downarrow \\
\text { p53/p21 and Caspase } \\
3 \uparrow\end{array}$ & {$[43]$} \\
\hline hAMSCs & Ovarian cancer & In vitro & miRNAs & Proliferation $\downarrow$ & $\begin{array}{l}\text { Activation of mito- } \\
\text { chondria-mediated } \\
\text { apoptosis signaling }\end{array}$ & {$[44]$} \\
\hline hAMSCS & $\begin{array}{l}\text { Metastatic prostate } \\
\text { cancer }\end{array}$ & In vitro and in vivo & miR-145 & $\begin{array}{l}\text { Proliferation } \downarrow \\
\text { Apoptosis } \uparrow\end{array}$ & $B C \mid x L \downarrow$ & {$[45]$} \\
\hline hBMSCs & Lung cancer & In vitro and in vivo & let-7i & $\begin{array}{l}\text { Proliferation } \downarrow \\
\text { Metastasis } \downarrow\end{array}$ & $\begin{array}{l}\text { KDM3A } \downarrow \\
\text { DCLK1 } 1 \\
\text { FXYD3 } \downarrow\end{array}$ & {$[46]$} \\
\hline hBMSCs & $\begin{array}{l}\text { Nasopharyngeal } \\
\text { carcinoma }\end{array}$ & In vitro and in vivo & N/A & $\begin{array}{l}\text { Proliferation } \uparrow \\
\text { Migration } \uparrow \\
\text { Tumorigenesis } \uparrow\end{array}$ & $\begin{array}{l}\text { FGF19-FGFR4 } \\
\text { dependent ERK } \\
\text { signaling cascade; } \\
\text { EMT }\end{array}$ & {$[47]$} \\
\hline hBMSCs & Osteosarcoma & In vitro and in vivo & IncRNA PVT1 & $\begin{array}{l}\text { Tumor growth } \uparrow \\
\text { Metastasis } \uparrow\end{array}$ & $\begin{array}{l}\text { Stabilize ERG and } \\
\text { sponge miR-183-5p }\end{array}$ & {$[48]$} \\
\hline hUCMSCs & Renal cancer & In vitro and in vivo & HGF mRNA & $\begin{array}{l}\text { Tumor growth } \uparrow \\
\text { Aggressiveness } \uparrow\end{array}$ & $\begin{array}{l}\text { Activation of AKT and } \\
\text { ERK1/2 signaling }\end{array}$ & [49] \\
\hline hUCMSCs & $\begin{array}{l}\text { Lung adenocarci- } \\
\text { noma cancer }\end{array}$ & In vitro and in vivo & miR-410 & $\begin{array}{l}\text { Proliferation } \uparrow \\
\text { Apoptosis } \downarrow\end{array}$ & PTEN $\downarrow$ & {$[50]$} \\
\hline hUCMSCs & Lung cancer & In vitro and in vivo & miR-130b-3p & $\begin{array}{l}\text { Proliferation } \uparrow \\
\text { Migration and inva- } \\
\text { sion } \uparrow \\
\text { Apoptosis } \downarrow\end{array}$ & $\begin{array}{l}\text { FOXO3 } \downarrow \\
\text { Activation of NFE2L2/ } \\
\text { TXNRD1 pathway }\end{array}$ & [51] \\
\hline hUCMSCs & Breast cancer & In vitro & N/A & $\begin{array}{l}\text { Proliferation } \uparrow \\
\text { Migration and inva- } \\
\text { sion } \uparrow\end{array}$ & $\begin{array}{l}\text { Induction of EMT via } \\
\text { the ERK pathway }\end{array}$ & {$[52]$} \\
\hline hBMSCs & $\begin{array}{l}\text { Non-small cell lung } \\
\text { cancer }\end{array}$ & In vitro and in vivo & Increased miR-21-5p & $\begin{array}{l}\text { Tumor growth } \uparrow \\
\text { Proliferation } \uparrow \\
\text { Invasion } \uparrow\end{array}$ & $\begin{array}{l}\text { Macrophage M2 } \\
\text { Polarization }\end{array}$ & [53] \\
\hline $\begin{array}{l}\text { hBMSCs of patients } \\
\text { with multiple } \\
\text { myeloma }\end{array}$ & Multiple myeloma & In vitro and in vivo & Lower miR-15a & $\begin{array}{l}\text { Tumor growth } \uparrow \\
\text { Dissemination } \uparrow\end{array}$ & $\begin{array}{l}\text { Oncogenic proteins, } \\
\text { cytokines, and } \\
\text { adhesion mol- } \\
\text { ecules } \uparrow\end{array}$ & [54] \\
\hline p53 deficient mBMSCs & Mouse gastric cancer & In vitro and in vivo & UBR2 & $\begin{array}{l}\text { Tumor growth } \uparrow \\
\text { Metastasis } \uparrow \\
\text { Stemness } \uparrow\end{array}$ & $\begin{array}{l}\text { Abnormal activation } \\
\text { of Wnt/B-catenin } \\
\text { signaling pathway }\end{array}$ & [55] \\
\hline
\end{tabular}


Table 2 (continued)

\begin{tabular}{|c|c|c|c|c|c|c|}
\hline EV source & Cancer & Method & Key cargo & Effect & $\begin{array}{l}\text { Proposed } \\
\text { mechanism }\end{array}$ & Reference \\
\hline hBMSCs & $\begin{array}{l}\text { Bone marrow-meta- } \\
\text { static breast cancer }\end{array}$ & In vitro and in vivo & miR-23b & $\begin{array}{l}\text { Proliferation and inva- } \\
\text { sion } \downarrow \\
\text { Sensitivity to doc- } \\
\text { etaxel } \downarrow \\
\text { Dormancy } \uparrow\end{array}$ & MARCKS $\downarrow$ & {$[60]$} \\
\hline hBMSCs & Breast carcinoma & In vitro & $\mathrm{N} / \mathrm{A}$ & $\begin{array}{c}\text { Proliferation and } \\
\text { migration } \downarrow \\
\text { Dormancy } \uparrow \\
\text { Anti-cancer drug } \\
\text { resistance } \uparrow\end{array}$ & MET & {$[61]$} \\
\hline hUCMSCs & $\begin{array}{l}\text { Breast cancer; ovarian } \\
\text { cancer }\end{array}$ & In vitro & $\mathrm{N} / \mathrm{A}$ & $\begin{array}{l}\text { Tumor heterogene- } \\
\text { ity } \uparrow \\
\text { Dormancy } \uparrow \\
\text { Tumor cell resist- } \\
\text { ance } \uparrow\end{array}$ & $\begin{array}{l}\text { Induction of MMP-2 } \\
\text { and ecto-5'- } \\
\text { nucleotidase } \\
\text { activity }\end{array}$ & {$[62]$} \\
\hline hUCMSCs & Gastric cancer & In vitro and in vivo & Proteins & Drug resistance $\uparrow$ & $\begin{array}{c}\text { CaM-Ks/Raf/MEK/ERK } \\
\text { signaling cascade } \uparrow\end{array}$ & {$[63]$} \\
\hline
\end{tabular}

EV extracellular vesicle, $h A M S C s$ human adipose mesenchymal stem cells, $h B M S C s$ human bone marrow mesenchymal stem cells, $h M e n S C s$ human menstrual stem cells, hUCMSCs human umbilical cord mesenchymal stem cells, mBMSCs mouse bone marrow mesenchymal stem cells, MSC mesenchymal stem cell

However, they are time-consuming and have low efficiency, typically leading to limited loading potential.

\section{Post-loading}

The post-loading occurs after EV isolation. The exogenous cargoes are encapsulated into EVs by passive loading or active loading.

Hydrophobic drugs can be combined with the EV lipid bilayer membrane after direct co-incubation, attaching to the EV surface. This passive loading strategy depends on the molecules' concentration gradient and the cargoes' hydrophobic nature, usually leading to a low loading capacity [65].

Regarding hydrophilic drugs, different active loading strategies have been proposed to temporarily permeabilize the hydrophobic lipid membrane, physically or chemically, allowing the diffusion of drugs into EVs. Physical approaches-such as electroporation, sonication, freeze and thaw cycles, extrusion-generally involve transient disruption of EV membrane by external forces [5]. Currently, electroporation is the most used one, especially for RNA encapsulation. Differently, chemical approaches utilize transfection reagents, or permeabilizers, such as saponin, to facilitate cargoes' entrance into the EV without destroying its lipid bilayer structure [66].

Each strategy has its advantages and limitations (summarized in Table 3). Overall, caution is required to avoid EV aggregation, EV membrane damage or immunogenicity induction during post-loading procedures [67-73].

\section{Novel technologies for cargo loading}

Recently, an optically reversible protein-protein interaction (EXPLORs) technology has been reported to encapsulate anti-inflammatory proteins into EVs [74]. In this case, cargo proteins are fused with the photoreceptor cryptochrome 2 (CRY2), and the basic-helix-loop helix 1 (CIB1) protein is fused with the EV surface protein CD9. CRY2 can bind with CIB1 under blue light irradiation (at $460 \mathrm{~nm}$ ), allowing the cargo packaging into EVs.

Additionally, some RNA binding proteins on the EV surface have been explored, such as Y-box protein 1 [75], ELVA protein HuR [76], and hnRNPA2B1 [77]. They can enable the specific loading of therapeutic RNAs into EVs.

\section{Surface engineering}

EVs derived from different cell sources have various surface molecules, displaying selectivity for specific recipient cells. Altering the surface of EVs, especially protein composition, can alter the biodistribution and tropism of EVs. The main goal of surface engineering is to endow EVs with additional targeting specificity, thereby increasing the local concentration of EVs at desired sites, reducing unwanted systemic toxicity. Surface engineering technologies can be classified into three categories: genetic engineering, chemical modification, and hybrid membrane engineering.

\section{Genetic engineering}

EVs have native transmembrane proteins that can be modified with exogenous targeting ligands. Genetic engineering is a valid method for displaying a targeting ligand on the EV membrane surface by parental cells 


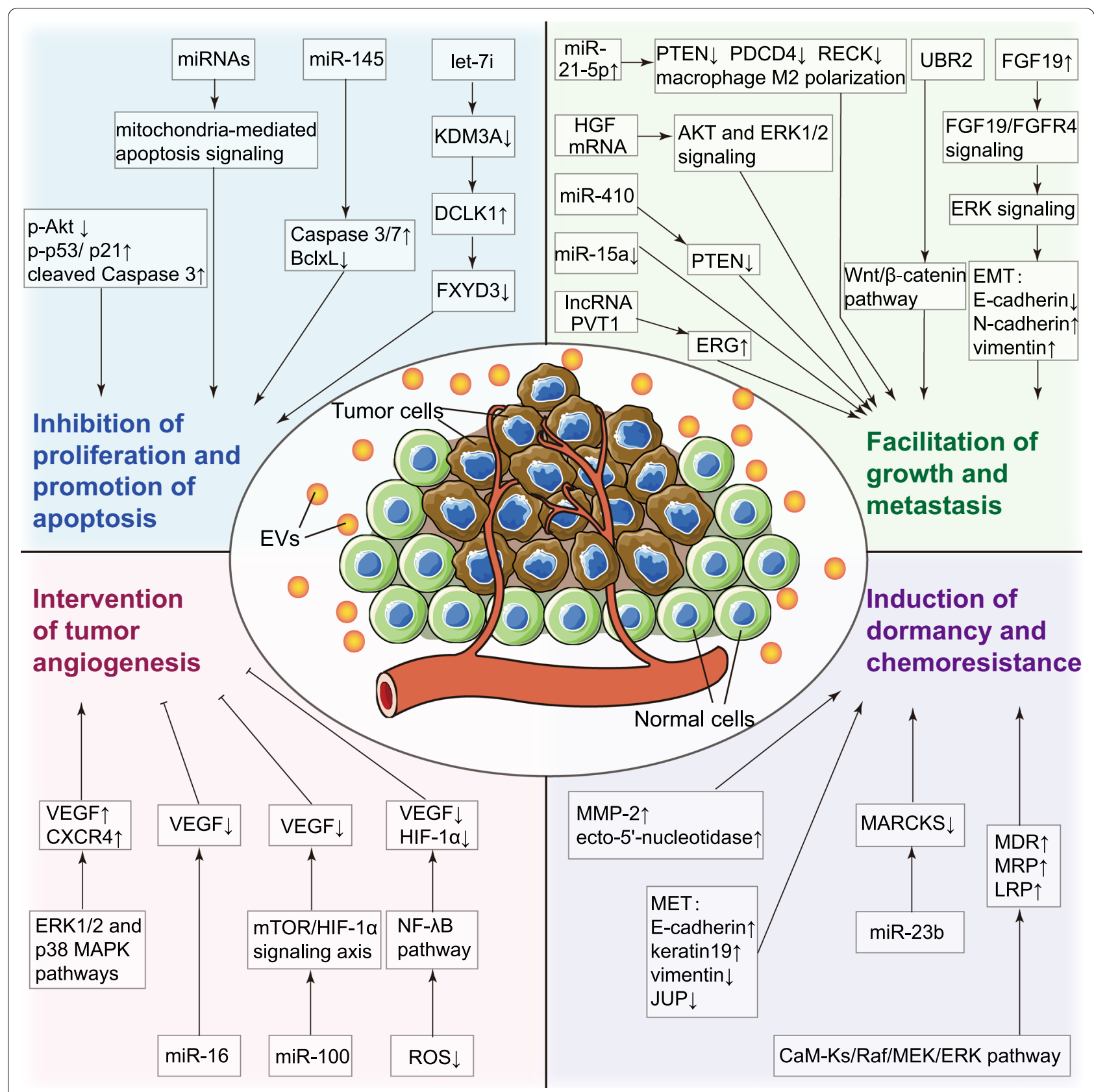

Fig. 2 Physiological functions of MSC-derived EVs in cancers

transfection with plasmids encoding the fusion protein of the targeting ligand and the selected EV transmembrane protein. Alternatively, the targeted epitope can also be inserted into the desired protein domain, instead of fusing with the whole protein [65].

Lysosomal-associated membrane protein 2 (Lamp2b), enriched in dendritic cell-derived exosomes, was the first reported and is the most widely used exosomal membrane protein in surface engineering approaches [78].
The N-terminus of Lamp2b is displayed on exosome surface and can be appended with different targeting ligands. For instance, the neuron-specific peptide rabies viral glycoprotein (RVG) [78], $\alpha \gamma$ integrin-specific peptide iRGD [79], and HER2-binding affibody zHER [80] have been anchored on EVs through fusion with Lamp2b to impart EVs with selective migration toward the central nervous system, integrin-positive breast cancer cells, and HER2-expressing tumor cells separately. 


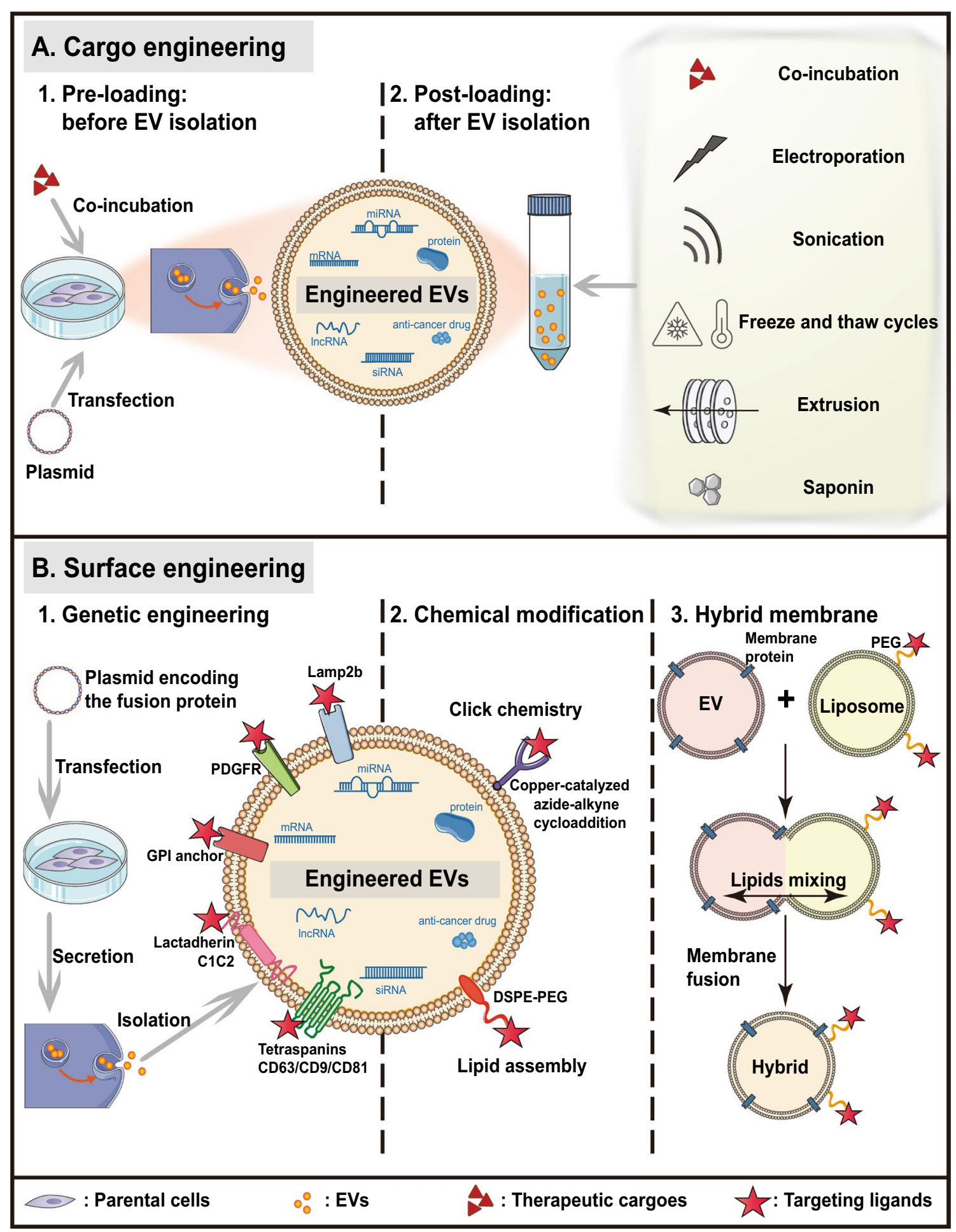

Fig. 3 Current technologies for EV bioengineering. EV bioengineering technologies are generally divided into two categories: cargo engineering (A) and surface engineering (B). DSPE 1,2-distearoyl-sn-glycero-3-phosphoethanolamine, GPI glycosylphosphatidylinositol, Lamp2b lysosomal-associated membrane protein 2, PDGFR platelet-derived growth factor receptor, PEG polyethylene glycol 
Table 3 Advantages and disadvantages of post-loading methods

\begin{tabular}{|c|c|c|c|c|}
\hline Post-loading method & Category & Advantages & Disadvantages & References \\
\hline Direct co-incubation & Passive loading & $\begin{array}{l}\text { Simple } \\
\text { Maintain EV membrane integrity }\end{array}$ & $\begin{array}{l}\text { Low loading efficiency } \\
\text { Time-consuming } \\
\text { Limited cargo range }\end{array}$ & {$[69,71]$} \\
\hline Electroporation & Physically-induced active loading & High loading efficiency & $\begin{array}{l}\text { SiRNA aggregation } \\
\text { Potential influence of stability }\end{array}$ & {$[70]$} \\
\hline Sonication & Physically-induced active loading & High loading efficiency & $\begin{array}{l}\text { Disrupt EV membrane integrity } \\
\text { Damage cargoes }\end{array}$ & {$[68,72]$} \\
\hline Freeze and thaw cycles & Physically-induced active loading & Medium loading efficiency & EV aggregation & {$[73]$} \\
\hline Extrusion & Physically-induced active loading & High loading efficiency & Disrupt EV membrane integrity & {$[68]$} \\
\hline Saponin/chemical transfection & Chemically-induced active loading & High loading efficiency & $\begin{array}{l}\text { Immunogenetic toxicity } \\
\text { Potential influence of stability }\end{array}$ & {$[66]$} \\
\hline
\end{tabular}

Despite these successes, a major limitation is that Lamp2b-inserted peptides are vulnerable to endosomal protease degradation. To improve the long-term stability of Lamp2b hybrids, a glycosylation motif (GNSTM) can be added to the peptide-Lamp2b fusions [81]. Besides, other membrane protein candidates have been investigated, such as the platelet-derived growth factor receptor (PDGFR) transmembrane domain [82], glycosylphosphatidylinositol (GPI) anchor peptides [83], the lactadherin $\mathrm{C} 1 \mathrm{C} 2$ domain [84], and the tetraspanin superfamily CD63/CD9/CD81 with their two extracellular loops [76, 85, 86]. They all exhibit excellent performance for functional ligand bearing with high binding affinity and selectivity to target tissues. However, such strategies are often time-consuming and challenging due to the complex manipulation of parental cells. They can also cause immune activation and functional losses of host proteins.

\section{Chemical modification}

Targeting ligands can also be attached to the EV surface by chemical modification after EV isolation, relying on bioconjugation reactions or lipid assembly.

Click chemistry is a representative technology that realizes the bioconjugation of targeting ligands to the EV surface by covalent bonds. EV membrane proteins' amine groups can be converted into alkyne groups and react with azide-tagged ligands via copper-catalyzed azidealkyne cycloaddition (CuAAC) [87]. For example, the azide-tagged $\alpha v \beta 3$ integrin-specific peptide c (RGDyK) [88] and glioma-targeting peptide RGE [87] have been successfully displayed on EV surfaces. However, the critical alkyne modification lacks site specificity control. Thus, click chemistry may jeopardize the structure and function of $\mathrm{EV}$ proteins.

Besides, lipids or amphipathic molecules can be inserted into EV lipid bilayer by lipid self-assembly, then tether targeting ligands to EV surface, comprising another chemical strategy [65]. The Polyethylene glycol-grafted 1,2-distearoyl-sn-glycero-3-phosphoethanolamine (DSPE-PEG) has been widely used to anchor targeting ligands on EV membranes for tumor-specific drug delivery since its FDA approval in medical applications [89]. Nevertheless, this method may also elicit higher toxicity of EVs.

\section{Hybrid membrane engineering}

EVs' lipid bilayer can spontaneously fuse with other membrane structures, such as synthetic liposomes. For example, Goh et al. have introduced a hybrid system named EXOPLEXs for direct membrane fusion between EVs and liposomes to efficiently deliver large molecules without compromising the EV membrane structure [90]. This hybrid membrane strategy also allowed EV surface modification by fusion with liposomes embedding multiple ligands.

Additionally, the hybridization of EVs with liposomes can be induced by polyethylene glycol (PEG) during freeze and thaw cycles to avoid immune system activation $[73,91]$. PEG can hide the hybrid system from immune cells by forming a hydration layer [92]. Therefore, the engineered EVs are endowed with lower immunogenicity, better stability, and prolonged circulation times.

\section{Advantages of MSC-derived EVs as ideal drug delivery vehicles \\ Comparison to EVs derived from body fluids}

EVs can be obtained from cell cultures or body fluids, such as blood, saliva, cerebrospinal fluid, urine, semen, and tracheal aspirates [4]. Although biological fluidderived EVs are promising detection tools for different disease diagnostic biomarkers, cell-derived EVs are nowadays the preferred choice for drug delivery. Upscaling EV production from body fluids is ethnically costly, therefore hard to implement in practice. Besides, body 
fluid-derived EVs often come from diverse cell types, leading to heterogeneity and interfering with follow-up analysis. For example, serum-derived EVs consist of EVs released by platelets, endothelial cells, and monocytes [27].

\section{Comparison to EVs derived from other cell sources}

All cells can secrete EVs. The most common cell sources include MSCs, immune cells, and cancer cells. Compared with other cell sources, MSCs are the most prolific EV producer and exhibit huge expansion capability for commercially sustainable EV production [6]. Additionally, MSCs can be isolated from different ethically uncontroversial human tissues and have been approved for clinical use by the FDA [93]. Like MSCs, MSC-derived EVs have been demonstrated to exhibit immunosuppressive activity and immunomodulatory properties, which would extend the EV-based drug delivery vehicle's useful live and cargo bioavailability [94]. Increasing clinical evidence has suggested that MSC-derived EVs have good therapeutic effects and are tolerated in different disease animal models without clear adverse effects [95]. Moreover, MSC-derived EVs also display high flexibility for modification and good stability during storage. Regarding other cell sources, current clinical research and applications of immune cell-derived EVs are focusing on their antigenpresenting capacity. They can be used as novel vaccination avenues, carrying intrinsically or extrinsically loaded antigens [96]. Similarly, cancer cell-derived EVs can elicit anti-cancer immune responses by cancer-associated antigen presentation. However, cancer cell-derived EVs can be dangerous because they may carry endogenous oncogenic factors and contribute to cancer [97]. Therefore, MSCs are especially suitable for the mass production of ideal EVs for drug delivery.

\section{Comparison to other nanocarriers}

Unlike traditional nanocarriers (e.g., liposomes), MSCderived EVs are naturally occurring endogenous vectors with higher biocompatibility and lower immunogenicity [98]. The immunoevasive property of MSC-derived EVs makes it easier for repeated administration because patients would not acquire immunity to the carriers after the first treatment, which currently is a major obstacle to mRNA and gene therapy [99]. Additionally, MSCderived EVs have better permeability and can freely cross certain biological barriers, such as the blood-retinal and the blood-brain barrier, showing bright prospects for eye and central nervous system diseases treatment [100]. Another significant advantage of MSC-derived EVs is their intrinsic tumor tropism inherited from their parental cells. Their complex surface proteins also provide engineering opportunities to enhance targeting capabilities with exogenous targeting ligands and other surface modification strategies. Instead, liposomes deliver their cargoes mostly through passive accumulation. Also, liposomes' complex functionalization has failed in clinical trials [101]. Besides, MSC-derived EVs can deliver their cargoes with minimal immune clearance and superior systemic retention in vivo, exhibiting substantial pharmacokinetic benefits $[4,102]$.

\section{Applications of bioengineered MSC-derived EVs in cancer therapy}

In the previous sections, we reviewed the recent technological progress for drug loading of therapeutic EVs and discussed the advantages of MSC-derived EVs as delivery vehicles. Based on these, in this section, we will detail the current applications of bioengineered MSC-derived EVs in cancer therapy.

\section{Loading anti-cancer cargoes}

As pointed out in this paper introduction, bioengineered MSC-derived EVs possess advantages as delivery vehicles in cancer therapy due to their strong tumor tropism, low immunogenicity, high tolerance, and nanoparticle characteristics [4]. Different anti-cancer cargoes can be packaged into MSC-derived EVs-including miRNAs, anti-miRNAs, siRNAs, mRNAs, drugs, and proteinsthrough modifications of either parental cells or EVs directly.

\section{Nucleic acids}

Many studies have shown that transfected MSCs can release EVs encapsulated with specific miRNAs. Once internalized, EVs can deliver miRNAs into cancer cells to regulate tumor development. O'Brien et al. [103] demonstrated that hBMSC-derived EVs loaded with miR379 suppressed breast cancer via COX-2 regulation. Likewise, miR-146b [104], miR-124a [105], and miR-34a [106] were introduced into glioma cells from transfected hBMSC-derived EVs and abrogated glioma growth by decreasing EGFR and NF- $k B$ protein, silencing FOXA2 and downregulating MYCN, respectively. Other miRNAs have been similarly packed into EVs and worked as anticancer agents by post-transcriptional tumor-related gene expression modulation in different cancers [107-117] (summarized in Table4).

Based on the fact that some miRNAs present protumor effects, corresponding inhibitory oligonucleotides can be arranged inside EVs and shuttled into tumor cells to reverse outcomes. For instance, Naseri et al. [118] successfully isolated exosomes from mouse BMSCs and loaded them with locked nucleic acid (LNA)-anti-miR$142-3 p$ by electroporation. The anti-miR-142-3p LNA was delivered to breast cancer cells via exosomes and 


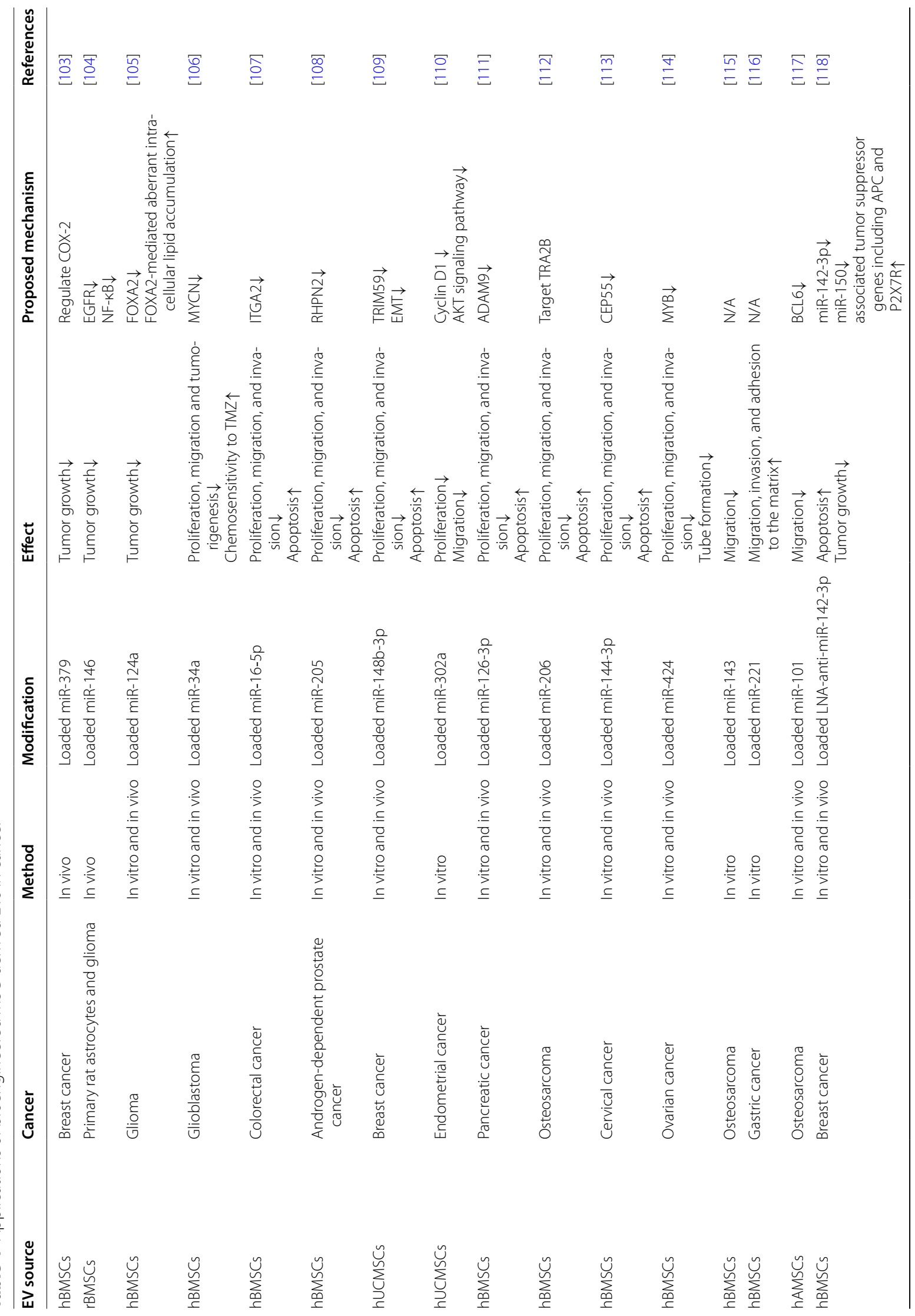




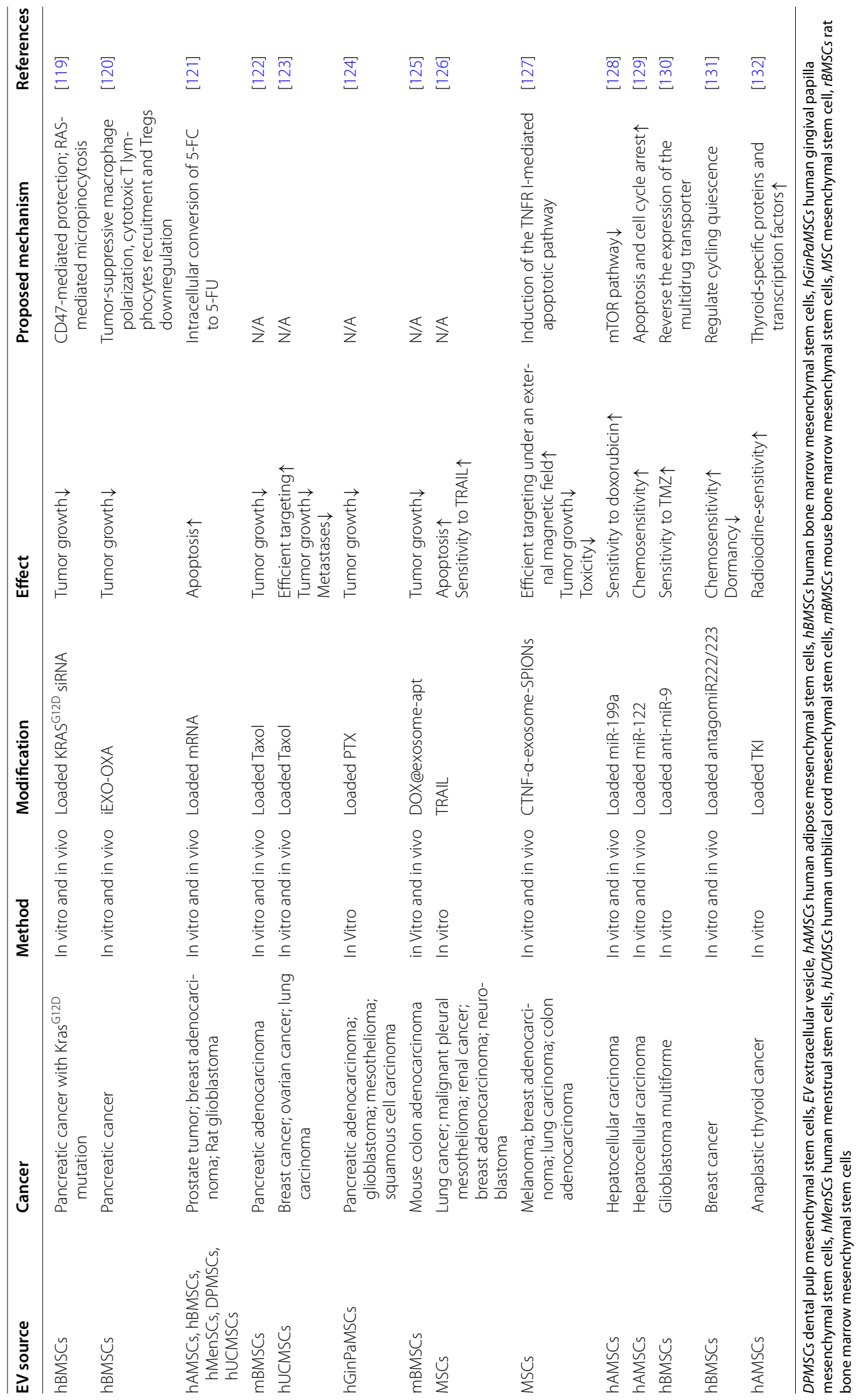


exhibited anti-tumor effects by miR-142-3p and miR-150 downregulation and subsequently enhancing anti-oncogenes (APC and P2X7R) transcription.

Small interfering RNAs (siRNAs) can also be loaded into exosomes by electroporation. A representative study generated hBMSC-derived exosomes using a bioreactor-based culture system. The exosomes were electroporated with siRNA targeting oncogenic KRAS ${ }^{\mathrm{G} 12 \mathrm{D}}$ [119]. The siRNA-exosome-based therapy suppressed $\mathrm{Kras}^{\mathrm{G} 12 \mathrm{D}}$ mutation pancreatic cancer with enhanced efficacy, both in vitro and in vivo. This effect was dependent on CD47-mediated protection and RASmediated micropinocytosis [95]. The valuable results have entered the Phase I clinical trial stage. Recently, Zhou et al. reported a significant exosome-based dual delivery biosystem, the iEXO-OXA [120]. In iEXOOXA, BMSC-derived exosomes were loaded with galectin-9 siRNA by electroporation and with oxaliplatin (OXA) prodrug by surface modification. Once internalized by pancreatic cancer cells, the galectin- 9 siRNA blocked the galectin-9/dectin-1 axis to enhance immunotherapy, and the OXA induced immunogenic tumor cell death. Therefore, they collectively suppressed tumor growth in pancreatic cancer.

Besides, mRNA loading of exosomes was investigated by genetic manipulation of parental MSCs. It has been demonstrated that exosomes derived from different MSCs transduced by retrovirus infection with the yCD::UPRT gene could carry the suicide gene mRNA [121]. Induced cell death occurred in the prodrug 5-FC presence by the 5 -FC conversion to 5 -FU upon suicide gene exosome internalization by tumor cells.

\section{Drugs}

Similarly, drugs can be incorporated into MSC-derived EVs using pre-loading or post-loading techniques. Regarding pre-loading, Pascucci et al. [122] demonstrated that mouse BMSCs packaged paclitaxel (PTX) after exposure to a very high PTX dosage in vitro for $24 \mathrm{~h}$. They released PTX into tumor cells via their exosomes, leading to tumor growth suppression in pancreatic adenocarcinoma. Melzer et al. [123] also reported a similar approach. They effectively isolated PTX-loaded exosomes from hUCMSC incubated with PTX for $24 \mathrm{~h}$. The PTX-loaded exosomes exhibited tumor growth and metastases inhibitory effects in breast cancer, lung cancer, and ovarian cancer. Similarly, human gingival papilla mesenchymal stem cells (hGinPaMSCs) were primed with a high PTX concentration. Then, the loaded PTX was released and incorporated into cancer cells via EVs to treat human pancreatic carcinoma and squamous carcinoma [124].
In another drug loading strategy, post-loading, the drug is directly packed into EVs after isolating them. For instance, Bagheri et al. [125] used mouse BMSCsderived exosomes to carry an anti-cancer drug, doxorubicin (DOX), by electroporation as a versatile platform for colorectal cancer treatment.

\section{Proteins}

Until now, only a few studies have been carried out applying protein-loaded MSC-derived EVs in anti-cancer therapy, among which tumor necrosis factor-related apoptosis-inducing ligand (TRAIL) is representative [126]. TRAIL is a promising anti-cancer protein and possesses the ability to selectively induce cancer cell apoptosis. It has been proved that TRAIL-transduced MSC-derived EVs can express membranal TRAIL. Then, the TRAIL delivery from EVs to cancer cells can induce apoptosis and abolish the TRAIL resistance in lung cancer, malignant pleural mesothelioma, renal cancer, breast adenocarcinoma, and neuroblastoma.

\section{Improving targeting specificity}

Despite native tumor-homing properties, researchers are still exploring new technologies to bring more robust targeting specificity to drug-loaded MSC-derived EVs. Exosome display technology is now widely investigated for exosome targeting by specific ligands attachment to the exosome membrane via surface engineering. Newly introduced membrane ligands endow exosomes with increased tumor tropism and lower systemic toxicity. Exosome membrane ligands' applications have been reported in many fields. Herein, we describe two applications in MSC-derived exosomes for cancer therapy.

Bagheri's study [125] (mentioned above) is an example. Before DOX loading, mouse BMSC-derived exosomes were tagged with the 5TR1 aptamer, which has a close affinity with MUC1 protein. MUC1 is an overexpressed transmembrane mucin glycoprotein in some cancer cells. The 5TR1 aptamer was attached to the exosomes' surface by covalent conjugation with surface amine groups via click chemistry. Therefore, the DOX@exosome-apt showed an enhanced tropism and effective inhibition for MUC1-positive cancer cells, providing safe and selective DOX delivery in colon adenocarcinoma.

Additionally, Zhuang et al. reported the CTNF- $\alpha$ exosome-SPIONs [127] that improved cancer targeting through magnetism and inhibited tumor growth by TNFR I-mediated apoptotic pathway induction. First, exosomes with TNF- $\alpha$ anchored in its membrane (CTNF- $\alpha$-exosomes) were isolated from MSCs transfected with plasmids encoding CTNF- $\alpha$. CTNF- $\alpha$ is a fusion peptide consisting of TNF- $\alpha$ and cell-penetrating 
peptides (CPP). It possesses the lipotropic activity of CPP, enabling TNF- $\alpha$ to anchor in the cell membrane. Next, transferrin-modified superparamagnetic iron oxide nanoparticles (SPIONs) were conjugated to the surface of the CTNF- $\alpha$-exosomes through transferrin-transferrin receptor interaction. SPIONs were used to deliver drugs to targeted areas by magnetic force. Finally, the CTNF$\alpha$-exosome-SPIONs were proved by in vitro and in vivo studies to exert anti-tumor effects under an external magnetic field by efficient TNF- $\alpha$ delivery to cancer cells' membrane-bound receptors.

\section{Enhancing chemosensitivity}

Besides, modified MSC-derived EVs can be utilized to confer tumor cells chemosensitivity via functional cargo loading and play assistant roles in cancer treatment. For example, miR-199a-transfected hAMSC-derived exosomes elicited enhanced chemosensitivity of hepatocellular carcinoma cells by targeting and subsequently inhibiting the mTOR pathway [128]. A similar effect was reported in miR-122-loaded exosomes from hAMSCs [129]. In another study, results indicated that anti-miR-9 delivery from hBMSC-derived exosomes to glioblastoma multiforme cells sensitized cancer cells to temozolomide [130]. Likewise, Bliss et al. [131] transfected hBMSCs with anti-miR-222/223 and demonstrated the anti-miR-222/223 could be loaded into breast cancer cells via exosomes to increase chemosensitivity. Recently, a new radioiodine-resistant thyroid cancer therapeutic approach via tyrosine kinase inhibitor (TKI)-loaded EVs has been proposed [132]. The TKI was encapsulated into hAMSC-derived EVs by direct incubation or sonication. Packaging efficiency differed, and the sonication was better. The iodine avidity of radioiodine-resistant thyroid cancer cells was abolished after the TKI-loaded EV treatment.

Applications of bioengineered MSC-derived EVs in oncology are summarized in Table 4 and Fig. 4. Once internalized by target cells, the modified EVs can release diverse bioactive constituents to regulate target signaling molecules and eventually impair tumor progression. MSC-derived EVs can also be designed to enhance targeting specificity, safety, and efficiency, being a promising therapeutic delivery vehicle. However, each modification method has its pros and cons. Indeed, EV bioengineering strategies are rapidly developing, and new technologies are emerging for different disease treatments with various parental cells, not limited to MSCs [133, 134]. In the future, these advanced technologies should also be used in MSC-derived EV-based anti-cancer agent delivery system.

\section{Future challenges and directions}

Clinical-grade MSC-derived exosomes encapsulated with Kras ${ }^{\mathrm{G} 12 \mathrm{D}}$ siRNA have been used to treat pancreatic cancer in multiple animal models, increasing mice's overall survival without any clear toxicity and improving targeting specificity $[95,119]$. Further investigation of the KRAS $^{\text {G12D }}$ siRNA-loaded exosome-based therapy has entered Phase I clinical trial for Kras ${ }^{\mathrm{G} 12 \mathrm{D}}$ mutation pancreatic cancer treatment. So far, 17 clinical trials using MSC-derived EVs as therapeutic avenues have been registered (listed in www.clinicaltrials.gov) [135] (Table 5). However, only one of them focuses on cancer treatment and few results are available. Many hurdles slow down the fledgling clinical utilization of MSC-derived EVs.

\section{Safety}

The dual roles of MSC-derived EVs in oncogenesis, tumor progression, and chemoresistance are highly variable, depending on MSC origins and tumor types. Therefore, the native MSC-derived EVs' safety controversy has long prevailed and is regarded as their "Achilles' heel" for clinical applications. The investigation into the impact of one EV type on one specific cancer and their mechanisms are necessary. Thus, the most appropriate MSC source might be screened for bioengineered EV production to treat the specific cancer type with fewer adverse effects. On the other hand, it is also needed to apply the same type of EVs to different cancers to determine the potential therapy scope. The development of methods to deactivate or remove unwanted and harmful EV contents may be a significant and novel engineering strategy. Moreover, MSC-derived EVs' long-term safety and therapeutic effects should be verified by future follow-ups. A monitoring platform in vivo is also required to obverse drug distribution, optimize dosage regimens, and guarantee therapeutic safety [3].

\section{Efficiency}

A second limitation of MSC-derived EV-based treatments is the heavy workload but low yield during production. Additionally, unsatisfactory drug loading and delivery efficiency seems to be common problems in all EV-related clinical applications. Their clinical breakthrough highly hinges on nanotechnology and genetic engineering advances.

During the past ten years, exosome-mimetics (EMs) have become prominent new drug delivery systems. They are bioinspired and synthetically personalized nanovesicles with similar characteristics and therapeutic effects of EVs $[136,137]$. Unlike EVs, EMs can be produced on a much larger scale by membrane filter extrusion, pressurization or slicing over microfluidic devices, and hybrid biomimicry strategies [138]. Interested readers might 


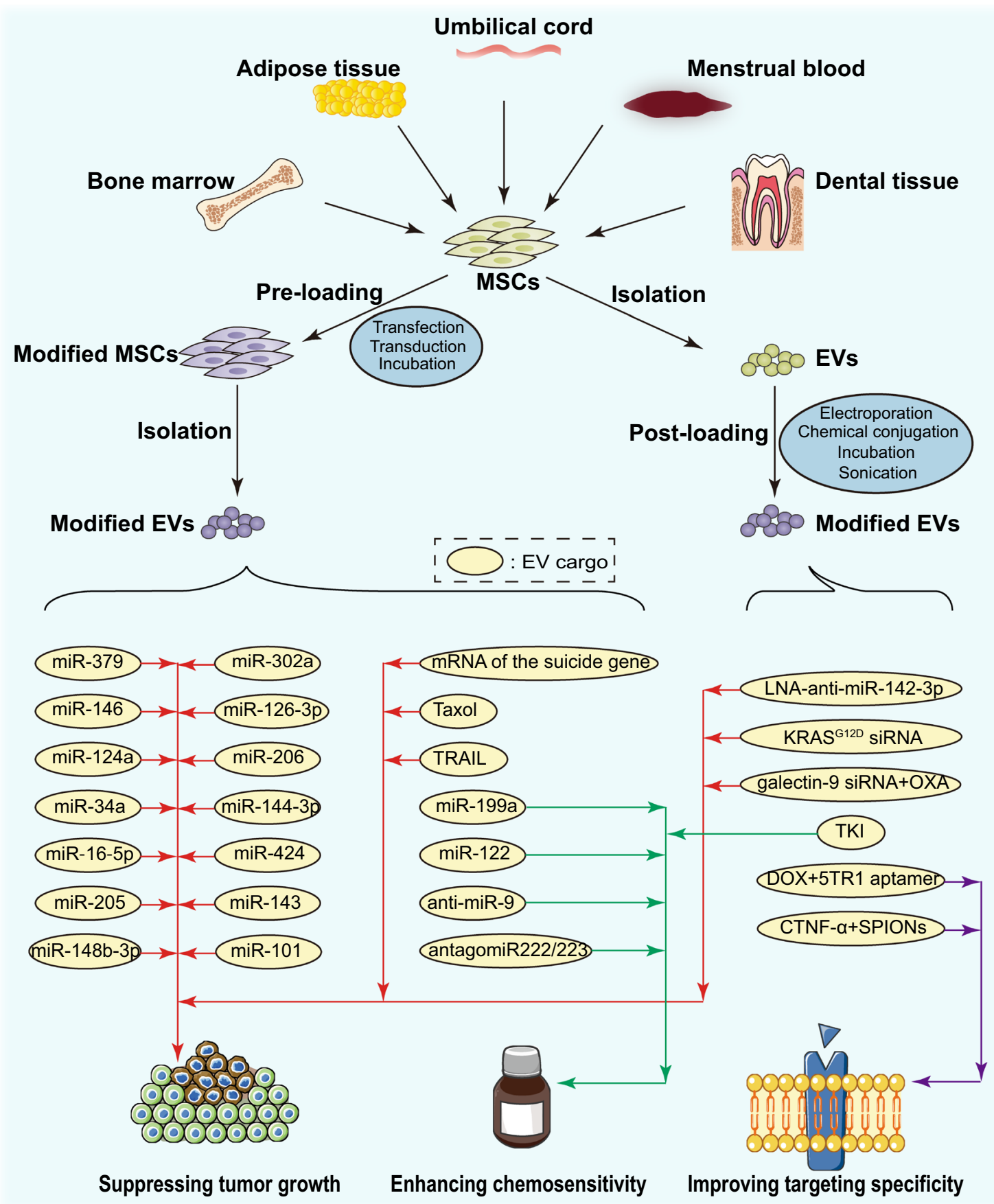

Fig. 4 Applications of bioengineered MSC-derived EVs in cancer therapy

refer to Antimisiaris [139] and Lu and Huang [138] for more detailed reviews on EM technologies and applications. Implementing MSCs-derived EMs in cancer treatment can be a future direction. For example, Kalimuthu et al. [140] have isolated EMs from hBMSCs mixed with PTX by extrusion and demonstrated their significant therapeutical effects against breast cancer. Similarly, EMs isolated from human induced pluripotent stem cells (iPSCs)-derived MSCs provided efficient DOX and docetaxel delivery to triple-negative breast cancer [141] and metastatic prostate cancer [142]. 
Table 5 Registered clinical trials involving MSC-derived EVs

\begin{tabular}{|c|c|c|c|c|c|}
\hline Identifier & Disease & EV source & Key cargo & Status & $\begin{array}{l}\text { Year of } \\
\text { registration }\end{array}$ \\
\hline NCT03384433 & Acute ischemic stroke & MSCs & miR-124 & Recruiting & 2017 \\
\hline NCT03437759 & Macular holes & UCMSCS & N/A & Active, not recruiting & 2018 \\
\hline NCT03608631 & Metastatic pancreas cancer with $\mathrm{Kras}^{\mathrm{G} 12 \mathrm{D}}$ mutation & BMSCs & KRAS $^{G 12 D}$ SiRNA & Recruiting & 2018 \\
\hline NCT03857841 & Bronchopulmonary Dysplasia & BMSCs & N/A & Active, not recruiting & 2019 \\
\hline NCT04134676 & Chronic Ulcer & WJ-MSCs & N/A & Completed & 2019 \\
\hline NCT04173650 & Dystrophic Epidermolysis Bullosa & BMSCs & N/A & Not yet recruiting & 2019 \\
\hline NCT04213248 & Dry eye related to cGVHD & UCMSCS & N/A & Recruiting & 2019 \\
\hline NCT04223622 & Osteoarthritis & AMSCS & N/A & Not yet recruiting & 2020 \\
\hline NCT04276987 & Severe novel coronavirus pneumonia & AMSCs & N/A & Completed & 2020 \\
\hline NCT04356300 & MODS after surgical repaire of ATAAD & UCMSCS & N/A & Not yet recruiting & 2020 \\
\hline NCT04388982 & Alzheimer's Disease & AMSCs & N/A & Recruiting & 2020 \\
\hline NCT04491240 & SARS-CoV-2 Associated Pneumonia & MSCs & N/A & Completed & 2020 \\
\hline NCT04544215 & $\begin{array}{l}\text { Carbapenem-resistant gram-negative bacilli-induced } \\
\text { pulmonary infection }\end{array}$ & AMSCs & N/A & Recruiting & 2020 \\
\hline NCT04602104 & ARDS & MSCs & N/A & Not yet recruiting & 2020 \\
\hline NCT04602442 & COVID-19 Associated Pneumonia & MSCs & N/A & Enrolling by invitation & 2020 \\
\hline NCT04657458 & COVID-19 associated ARDS & BMSCs & N/A & Available & 2020 \\
\hline NCT04798716 & ARDS or NCP caused by COVID-19 & MSCs & N/A & Not yet recruiting & 2021 \\
\hline
\end{tabular}

AMSCs adipose mesenchymal stem cells, $A R D S$ acute respiratory distress syndrome, ATAAD acute type A aortic dissection, $B M S C s$ bone marrow mesenchymal stem cells, CGVHD chronic graft versus host diseases, EV extracellular vesicle, MODS multiple organ dysfunction syndrome, $M S C$ mesenchymal stem cell, NCP novel coronavirus pneumonia, UCMSCs umbilical cord mesenchymal stem cells, WJ-MSCs Wharton's Jelly mesenchymal stem cells

Besides, the therapeutical efficiency also depends on MSCs' availability and expandability. Currently, bone marrow MSCs are the most frequently used, followed by the umbilical cord MSCs and adipose MSCs. In further research, menstrual blood MSCs and dental tissue MSCs deserve more attention due to their convenient and noninvasive accessibility. Concerning expandability, human induced pluripotent stem cells (iPSCs) have been used to produce MSCs with limitless expandability, in theory [143-145]. Increasing efforts are still required to ensure the efficacy of EVs derived from these MSCs.

\section{Standardization}

A recently published paper presented isolation and characterization protocols for six different EV subpopulations from tissues [146]. However, EV classification has not yet been unified. Definitions such as extracellular vesicles, microvesicles, and exosomes are obscure and inconsistent among past studies. Additionally, some findings may be derived from several heterogeneous subpopulations [4]. Further research should distinguish different MSCderived EV subpopulations and elucidate their respective roles in cancer development. A more comprehensive understanding of intercellular communications between cancer cells and MSC-derived EVs may also provide novel insights into cancer biology and pave the way for MSCderived EV-based drug delivery systems. Considering
EVs' functional complexity and heterogeneity, there is an urgent need to establish refined systematic standards for the culture conditions, modification, production, purification, characterization, and storage of bioengineered MSC-derived EVs before clinical applications.

\section{Conclusions}

Overall, MSC-derived EVs can present multiple effects on tumor development and serve as promising antitumor drug delivery platforms due to their strong tumor tropism. However, the utilization of MSC-derived EVs in cancer treatment is still at the beginning. Further studies are required to accelerate their therapeutic clinic application.

\footnotetext{
Abbreviations

5-FC: 5-Fluorocytosine; 5-FU: 5-Fluorouracil; AFM: Atomic force microscopy; AMSCs: Adipose mesenchymal stem cells; ARDS: Acute respiratory distress syndrome; ATAAD: Acute type A aortic dissection; BMSCs: Bone marrow mesenchymal stem cells; CGVHD: Chronic graft versus host diseases; CIB1: Basic-helix-loop helix 1; CPP: Cell-penetrating peptides; CRY2: Photoreceptor cryptochrome 2; CuAAC: Copper-catalyzed azide-alkyne cycloaddition; DLS: Dynamic light scattering; DOX: Doxorubicin; DPMSCs: Dental pulp mesenchymal stem cells; DSPE: 1,2-Distearoyl-sn-glycero-3-phosphoethanolamine; EM: Electron microscopy; EMs: Exosome-mimetics; EMT: Epithelial-mesenchymal transition; ER: Endoplasmic reticulum; ESE: Early-sorting endosome; EV: Extracellular vesicle; FC: Flow cytometry; GNSTM: Glycosylation motif; GPI: Glycosylphosphatidylinositol; hAMSCs: Human adipose mesenchymal stem cells; hBMSCs: Human bone marrow mesenchymal stem cells; HGF: Hepatocyte growth factor; hGinPaMSCs: Human gingival papilla mesenchymal stem
} 
cells; hMenSCs: Human menstrual stem cells; hUCMSCs: Human umbilical cord mesenchymal stem cells; ILV: Intraluminal vesicle; iPSCs: Induced pluripotent stem cells; ISEV: International Society for Extracellular Vesicles; Lamp2b: Lysosomal-associated membrane protein 2; LNA: Locked nucleic acid; LSE: Latesorting endosome; mBMSCs: Mouse bone marrow mesenchymal stem cells; MET: Mesenchymal-epithelial transition; MODS: Multiple organ dysfunction syndrome; MSC: Mesenchymal stem cell; MVB: Multivesicular body; NCP: Novel coronavirus pneumonia; NTA: Nanoparticle tracking analysis; OXA: Oxaliplatin; PDGFR: Platelet-derived growth factor receptor; PEG: Polyethylene glycol; PTX: Paclitaxel; rBMSCs: Rat bone marrow mesenchymal stem cells; ROS: Reactive oxygen species; RVG: Rabies viral glycoprotein; SEM: Scanning electron microscopy; SiRNAs: Small interfering RNAs; SPIONs: Superparamagnetic iron oxide nanoparticles; TEM: Transmission electron microscopy; TKI: Tyrosine kinase inhibitor; TRAIL: Tumor necrosis factor-related apoptosis-inducing ligand; TRPS: Tunable resistance pulse sensing; UCMSCs: Umbilical cord mesenchymal stem cells; WJ-MSCs: Wharton's Jelly mesenchymal stem cells.

\section{Acknowledgements}

Not applicable.

\section{Authors' contributions}

$\mathrm{LL}, \mathrm{ZW}$, and $\mathrm{BZ}$ contributed to conception and design of the study. ZW and BZ wrote the manuscript. CW, FY, BH, BL, and LL reviewed and edited the manuscript. All authors contributed to manuscript revision, read and approved the final manuscript

\section{Funding}

This study was supported by the National Natural Science Foundation of China (No. 81972538) and China Postdoctoral Science Foundation (No. 2020M683333).

\section{Availability of data and materials \\ Not applicable.}

\section{Declarations}

\section{Ethics approval and consent to participate}

Not applicable.

\section{Consent for publication}

All authors consent to publication.

\section{Competing interests}

ZW and BZ contributed equally to the work and should be regarded as co-first authors. $\mathrm{LL}$ and $\mathrm{BL}$ are co-corresponding authors. The other authors have no conflicts of interest to declare.

\section{Author details}

'State Key Laboratory of Oral Diseases, National Clinical Research Center for Oral Diseases, Department of Head and Neck Oncology, West China Hospital of Stomatology, Sichuan University, Chengdu, China. ${ }^{2}$ State Key Laboratory of Oral Diseases, National Clinical Research Center for Oral Diseases, Department of Comfort Care Dental Center, West China Hospital of Stomatology, Sichuan University, Chengdu, China. ${ }^{3}$ State Key Laboratory of Oral Diseases, National Clinical Research Center for Oral Diseases, West China Hospital of Stomatology, Sichuan University, Chengdu, China. ${ }^{4}$ State Key Laboratory of Oral Diseases, National Clinical Research Center for Oral Diseases, Department of Orthodontics, West China Hospital of Stomatology, Sichuan University, Chengdu, China.

Received: 19 May 2021 Accepted: 16 August 2021 Published online: 03 September 2021

\section{References}

1. El Andaloussi S, Maeger I, Breakefield XO, Wood MJA. Extracellular vesicles: biology and emerging therapeutic opportunities. Nat Rev Drug Discovery. 2013;12(5):348-58.
2. Wolf $\mathrm{P}$. The nature and significance of platelet products in human plasma. Br J Haematol. 1967;13(3):269-88.

3. de Abreu RC, Fernandes H, da Costa Martins PA, Sahoo S, Emanueli C, Ferreira L. Native and bioengineered extracellular vesicles for cardiovascular therapeutics. Nat Rev Cardiol. 2020;17(11):685-97.

4. Kalluri R, LeBleu VS. The biology, function, and biomedical applications of exosomes. Science. 2020;367(6478):eaau6977.

5. Walker S, Busatto S, Pham A, Tian M, Suh A, Carson K, et al. Extracellular vesicle-based drug delivery systems for cancer treatment. Theranostics. 2019;9(26):8001-17.

6. Yeo RW, Lai RC, Zhang B, Tan SS, Yin Y, Teh BJ, et al. Mesenchymal stem cell: an efficient mass producer of exosomes for drug delivery. Adv Drug Deliv Rev. 2013;65(3):336-41.

7. Prockop DJ. Marrow stromal cells as stem cells for nonhematopoietic tissues. Science. 1997;276(5309):71-4.

8. Pittenger MF, Mackay AM, Beck SC, Jaiswal RK, Douglas R, Mosca JD, et al. Multilineage potential of adult human mesenchymal stem cells. Science. 1999;284(5411):143-7.

9. Erices $\mathrm{A}$, Conget $\mathrm{P}$, Minguell JJ. Mesenchymal progenitor cells in human umbilical cord blood. Br J Haematol. 2000;109(1):235-42.

10. Gang EJ, Jeong JA, Hong SH, Hwang SH, Kim SW, Yang IH, et al. Skeletal myogenic differentiation of mesenchymal stem cells isolated from human umbilical cord blood. Stem Cells. 2004;22(4):617-24.

11. In 't Anker PS, Scherjon SA, Kleijburg-van der Keur C, de GrootSwings GM, Claas FH, Fibbe WE, et al. Isolation of mesenchymal stem cells of fetal or maternal origin from human placenta. Stem Cells. 2004;22(7):1338-45.

12. Parolini O, Alviano F, Bagnara GP, Bilic G, Bühring HJ, Evangelista M, et al. Concise review: isolation and characterization of cells from human term placenta: outcome of the first international workshop on placenta derived stem cells. Stem Cells. 2008;26(2):300-11.

13. Zuk PA, Zhu M, Ashjian P, De Ugarte DA, Huang Jl, Mizuno H, et al. Human adipose tissue is a source of multipotent stem cells. Mol Biol Cell. 2002;13(12):4279-95.

14. Bunnell BA, Flaat M, Gagliardi C, Patel B, Ripoll C. Adipose-derived stem cells: isolation, expansion and differentiation. Methods. 2008;45(2):115-20.

15. Liu J, Yu F, Sun Y, Jiang B, Zhang W, Yang J, et al. Concise reviews: characteristics and potential applications of human dental tissue-derived mesenchymal stem cells. Stem Cells. 2015;33(3):627-38.

16. Tomasello L, Mauceri R, Coppola A, Pitrone M, Pizzo G, Campisi G, et al. Mesenchymal stem cells derived from inflamed dental pulpal and gingival tissue: a potential application for bone formation. Stem Cell Res Ther. 2017:8(1):179.

17. Pittenger MF, Discher DE, Peault BM, Phinney DG, Hare JM, Caplan Al. Mesenchymal stem cell perspective: cell biology to clinical progress. NPJ Regen Med. 2019;4:22.

18. Shi Y, Du L, Lin L, Wang Y. Tumour-associated mesenchymal stem/ stromal cells: emerging therapeutic targets. Nat Rev Drug Discov. 2017;16(1):35-52.

19. Studeny M, Marini FC, Dembinski JL, Zompetta C, Cabreira-Hansen $\mathrm{M}$, Bekele BN, et al. Mesenchymal stem cells: potential precursors for tumor stroma and targeted-delivery vehicles for anticancer agents. J Natl Cancer Inst. 2004;96(21):1593-603.

20. Kucerova L, Altanerova V, Matuskova M, Tyciakova S, Altaner C. Adipose tissue-derived human mesenchymal stem cells mediated prodrug cancer gene therapy. Cancer Res. 2007;67(13):6304-13.

21. Xin H, Kanehira M, Mizuguchi H, Hayakawa T, Kikuchi T, Nukiwa T, et al. Targeted delivery of CX3CL1 to multiple lung tumors by mesenchymal stem cells. Stem Cells. 2007;25(7):1618-26.

22. Kidd S, Spaeth E, Dembinski JL, Dietrich M, Watson K, Klopp A, et al. Direct evidence of mesenchymal stem cell tropism for tumor and wounding microenvironments using in vivo bioluminescent imaging. Stem Cells. 2009;27(10):2614-23.

23. Spees JL, Lee RH, Gregory CA. Mechanisms of mesenchymal stem/ stromal cell function. Stem Cell Res Ther. 2016;7:125.

24. Kosaka N, Yoshioka Y, Fujita Y, Ochiya T. Versatile roles of extracellular vesicles in cancer. J Clin Invest. 2016;126(4):1163-72.

25. Baek G, Choi H, Kim Y, Lee HC, Choi C. Mesenchymal stem cell-derived extracellular vesicles as therapeutics and as a drug delivery platform. Stem Cells TransI Med. 2019;8(9):880-6. 
26. Massa M, Croce S, Campanelli R, Abba C, Lenta E, Valsecchi C, et al. Clinical applications of mesenchymal stem/stromal cell derived extracellular vesicles: therapeutic potential of an acellular product. Diagnostics (Basel). 2020;10(12):999.

27. Wang J, Chen D, Ho EA. Challenges in the development and establishment of exosome-based drug delivery systems. J Control Release. 2021;329:894-906.

28. Gardiner C, Di Vizio D, Sahoo S, Thery C, Witwer KW, Wauben M, et al. Techniques used for the isolation and characterization of extracellular vesicles: results of a worldwide survey. J Extracell Vesicles. 2016;5:32945.

29. Zhu L, Sun HT, Wang S, Huang SL, Zheng Y, Wang CQ, et al. Isolation and characterization of exosomes for cancer research. J Hematol Oncol. 2020;13(1):152.

30. Thery C, Witwer KW, Aikawa E, Alcaraz MJ, Anderson JD, Andriantsitohaina R, et al. Minimal information for studies of extracellular vesicles 2018 (MISEV2018): a position statement of the International Society for Extracellular Vesicles and update of the MISEV2014 guidelines. J Extracell Vesicles. 2018;7(1):1535750.

31. Tauro BJ, Greening DW, Mathias RA, Ji H, Mathivanan S, Scott AM, et al. Comparison of ultracentrifugation, density gradient separation, and immunoaffinity capture methods for isolating human colon cancer cell line LIM1863-derived exosomes. Methods. 2012;56(2):293-304.

32. Boing AN, van der Pol E, Grootemaat AE, Coumans FA, Sturk A, Nieuwland R. Single-step isolation of extracellular vesicles by size-exclusion chromatography. J Extracell Vesicles. 2014;3:23430.

33. Heinemann ML, IImer M, Silva LP, Hawke DH, Recio A, Vorontsova MA, et al. Benchtop isolation and characterization of functional exosomes by sequential filtration. J Chromatogr A. 2014;1371:125-35.

34. Greening DW, Xu R, Ji H, Tauro BJ, Simpson RJ. A protocol for exosome isolation and characterization: evaluation of ultracentrifugation, density-gradient separation, and immunoaffinity capture methods. Methods Mol Biol. 2015;1295:179-209.

35. McNamara RP, Caro-Vegas CP, Costantini LM, Landis JT, Griffith JD, Damania BA, et al. Large-scale, cross-flow based isolation of highly pure and endocytosis-competent extracellular vesicles. J Extracell Vesicles. 2018;7(1):1541396.

36. Varderidou-Minasian S, Lorenowicz MJ. Mesenchymal stromal/stem cell-derived extracellular vesicles in tissue repair: challenges and opportunities. Theranostics. 2020;10(13):5979-97.

37. Zhu W, Huang L, Li Y, Zhang X, Gu J, Yan Y, et al. Exosomes derived from human bone marrow mesenchymal stem cells promote tumor growth in vivo. Cancer Lett. 2012;315(1):28-37.

38. Lee JK, Park SR, Jung BK, Jeon YK, Lee YS, Kim MK, et al. Exosomes derived from mesenchymal stem cells suppress angiogenesis by down-regulating VEGF expression in breast cancer cells. PLOS ONE. 2013;8(12):e84256.

39. Pakravan K, Babashah S, Sadeghizadeh M, Mowla SJ, MossahebiMohammadi M, Ataei F, et al. MicroRNA-100 shuttled by mesenchymal stem cell-derived exosomes suppresses in vitro angiogenesis through modulating the mTOR/HIF-1 alpha/NEGF signaling axis in breast cancer cells. Cell Oncol. 2017;40(5):457-70.

40. Alcayaga-Miranda F, González PL, Lopez-Verrilli A, Varas-Godoy M, Aguila-Díaz C, Contreras L, et al. Prostate tumor-induced angiogenesis is blocked by exosomes derived from menstrual stem cells through the inhibition of reactive oxygen species. Oncotarget. 2016;7(28):44462-77.

41. Rosenberger L, Ezquer M, Lillo-Vera F, Pedraza PL, Ortuzar MI, Gonzalez $\mathrm{PL}$, et al. Stem cell exosomes inhibit angiogenesis and tumor growth of oral squamous cell carcinoma. Sci Rep. 2019;9(1):663.

42. Bruno S, Collino F, Deregibus MC, Grange C, Tetta C, Camussi G. Microvesicles derived from human bone marrow mesenchymal stem cells inhibit tumor growth. Stem Cells Dev. 2013;22(5):758-71.

43. Wu S, Ju GQ, Du T, Zhu YJ, Liu GH. Microvesicles derived from human umbilical cord Wharton's jelly mesenchymal stem cells attenuate bladder tumor cell growth in vitro and in vivo. PLoS ONE. 2013;8(4):e61366.

44. Reza A, Choi YJ, Yasuda H, Kim JH. Human adipose mesenchymal stem cell-derived exosomal-miRNAs are critical factors for inducing antiproliferation signalling to A2780 and SKOV-3 ovarian cancer cells. Sci Rep. 2016;6:38498.
45. Takahara K, li M, Inamoto T, Nakagawa T, Ibuki N, Yoshikawa Y, et al. microRNA-145 mediates the inhibitory effect of adipose tissue-derived stromal cells on prostate cancer. Stem Cells Dev. 2016;25(17):1290-8.

46. Liu J, Feng Y, Zeng X, He M, Gong Y, Liu Y. Extracellular vesiclesencapsulated let-7i shed from bone mesenchymal stem cells suppress lung cancer via KDM3A/DCLK1/FXYD3 axis. J Cell Mol Med. 2021;25(4):1911-26.

47. Shi S, Zhang Q, Xia Y, You B, Shan Y, Bao L, et al. Mesenchymal stem cellderived exosomes facilitate nasopharyngeal carcinoma progression. Am J Cancer Res. 2016;6(2):459-72.

48. Zhao W, Qin P, Zhang D, Cui X, Gao J, Yu Z, et al. Long non-coding RNA PVT1 encapsulated in bone marrow mesenchymal stem cellderived exosomes promotes osteosarcoma growth and metastasis by stabilizing ERG and sponging miR-183-5p. Aging (Albany NY). 2019;11(21):9581-96.

49. Du T, Ju G, Wu S, Cheng Z, Cheng J, Zou X, et al. Microvesicles derived from human Wharton's jelly mesenchymal stem cells promote human renal cancer cell growth and aggressiveness through induction of hepatocyte growth factor. PLoS ONE. 2014;9(5):e96836.

50. Dong L, Pu Y, Zhang L, Qi Q, Xu L, Li W, et al. Human umbilical cord mesenchymal stem cell-derived extracellular vesicles promote lung adenocarcinoma growth by transferring miR-410. Cell Death Dis. 2018;9(2):218

51. Guo Q, Yan J, Song T, Zhong C, Kuang J, Mo Y, et al. microRNA-130b-3p contained in MSC-derived EVs promotes lung cancer progression by regulating the FOXO3/NFE2L2/TXNRD1 axis. Mol Ther Oncolytics. 2021;20:132-46.

52. Zhou X, Li T, Chen Y, Zhang N, Wang P, Liang Y, et al. Mesenchymal stem cellderived extracellular vesicles promote the in vitro proliferation and migration of breast cancer cells through the activation of the ERK pathway. Int J Oncol. 2019;54(5):1843-52.

53. Ren W, Hou J, Yang C, Wang H, Wu S, Wu Y, et al. Extracellular vesicles secreted by hypoxia pre-challenged mesenchymal stem cells promote non-small cell lung cancer cell growth and mobility as well as macrophage M2 polarization via miR-21-5p delivery. J Exp Clin Cancer Res. 2019;38(1):62.

54. Roccaro AM, Sacco A, Maiso P, Azab AK, Tai YT, Reagan M, et al. BM mesenchymal stromal cell-derived exosomes facilitate multiple myeloma progression. J Clin Invest. 2013;123(4):1542-55.

55. Mao J, Liang Z, Zhang B, Yang H, Li X, Fu H, et al. UBR2 Enriched in p53 deficient mouse bone marrow mesenchymal stem cell-exosome promoted gastric cancer progression via Wnt/beta-catenin pathway. Stem Cells. 2017;35(11):2267-79.

56. Yang J, Antin P, Berx G, Blanpain C, Brabletz T, Bronner M, et al. Guidelines and definitions for research on epithelial-mesenchymal transition. Nat Rev Mol Cell Biol. 2020;21 (6):341-52.

57. Gomis RR, Gawrzak S. Tumor cell dormancy. Mol Oncol. 2017;11(1):62-78

58. Fornetti J, Welm AL, Stewart SA. Understanding the bone in cancer metastasis. J Bone Miner Res. 2018;33(12):2099-113.

59. Haider MT, Smit DJ, Taipaleenmaki H. The endosteal niche in breast cancer bone metastasis. Front Oncol. 2020;10:335.

60. Ono M, Kosaka N, Tominaga N, Yoshioka Y, Takeshita F, Takahashi R-U, et al. Exosomes from bone marrow mesenchymal stem cells contain a microRNA that promotes dormancy in metastatic breast cancer cells. Sci Signal. 2014;7(332):ra63.

61. Casson J, Davies OG, Smith CA, Dalby MJ, Berry CC. Mesenchymal stem cell-derived extracellular vesicles may promote breast cancer cell dormancy. J Tissue Eng. 2018;9:2041731418810093.

62. Yang Y, Bucan V, Baehre H, von der Ohe J, Otte A, Hass R. Acquisition of new tumor cell properties by MSC-derived exosomes. Int J Oncol. 2015:47(1):244-52.

63. Ji R, Zhang B, Zhang X, Xue J, Yuan X, Yan Y, et al. Exosomes derived from human mesenchymal stem cells confer drug resistance in gastric cancer. Cell Cycle. 2015;14(15):2473-83.

64. Herrmann IK, Wood MJA, Fuhrmann G. Extracellular vesicles as a next-generation drug delivery platform. Nat Nanotechnol. 2021;16(7):748-59. 
65. Liang Y, Duan L, Lu J, Xia J. Engineering exosomes for targeted drug delivery. Theranostics. 2021;11(7):3183-95.

66. Haney MJ, Klyachko NL, Harrison EB, Zhao Y, Kabanov AV, Batrakova EV.TPP1 delivery to lysosomes with extracellular vesicles and their enhanced brain distribution in the animal model of batten disease. Adv Healthc Mater. 2019;8(11):e1801271.

67. Fuhrmann G, Serio A, Mazo M, Nair R, Stevens MM. Active loading into extracellular vesicles significantly improves the cellular uptake and photodynamic effect of porphyrins. J Control Release. 2015;205:35-44.

68. Cho N-J, Hwang LY, Solandt JJR, Frank CW. Comparison of extruded and sonicated vesicles for planar bilayer self-assembly. Materials (Basel). 2013;6(8):3294-308

69. Haney MJ, Klyachko NL, Zhao Y, Gupta R, Plotnikova EG, He Z, et al. Exosomes as drug delivery vehicles for Parkinson's disease therapy. J Control Release. 2015;207:18-30.

70. Johnsen KB, Gudbergsson JM, Skov MN, Christiansen G, Gurevich $L, M o o s T$, et al. Evaluation of electroporation-induced adverse effects on adipose-derived stem cell exosomes. Cytotechnology. 2016;68(5):2125-38

71. Kim MS, Haney MJ, Zhao Y, Mahajan V, Deygen I, Klyachko NL, et al. Development of exosome-encapsulated paclitaxel to overcome MDR in cancer cells. Nanomed Nanotechnol Biol Med. 2016;12(3):655-64.

72. Lamichhane TN, Jeyaram A, Patel DB, Parajuli B, Livingston NK, Arumugasaamy N, et al. Oncogene knockdown via active loading of small RNAs into extracellular vesicles by sonication. Cell Mol Bioeng. 2016;9(3):315-24.

73. Sato YT, Umezaki K, Sawada S, Mukai SA, Sasaki Y, Harada N, et al. Engineering hybrid exosomes by membrane fusion with liposomes. Sci Rep. 2016;6:21933.

74. Yim N, Ryu S-W, Choi K, Lee KR, Lee S, Choi H, et al. Exosome engineering for efficient intracellular delivery of soluble proteins using optically reversible protein-protein interaction module. Nat Commun. 2016;7:12277

75. Shurtleff MJ, Temoche-Diaz MM, Karfilis KV, Ri S, Schekman R. Y-box protein 1 is required to sort microRNAs into exosomes in cells and in a cell-free reaction. Elife. 2016:5:e19276.

76. Li Z, Zhou X, Wei M, Gao X, Zhao L, Shi R, et al. In vitro and in vivo RNA inhibition by CD9-HuR functionalized exosomes encapsulated with miRNA or CRISPR/dCas9. Nano Lett. 2019;19(1):19-28.

77. Villarroya-Beltri C, Gutiérrez-Vázquez C, Sánchez-Cabo F, Pérez-Hernández D, Vázquez J, Martin-Cofreces N, et al. Sumoylated hnRNPA2B1 controls the sorting of miRNAs into exosomes through binding to specific motifs. Nat Commun. 2013;4:2980.

78. Alvarez-Erviti L, Seow Y, Yin H, Betts C, Lakhal S, Wood MJA. Delivery of siRNA to the mouse brain by systemic injection of targeted exosomes. Nat Biotechnol. 2011;29(4):341-5.

79. Tian Y, Li S, Song J, Ji T, Zhu M, Anderson GJ, et al. A doxorubicin delivery platform using engineered natural membrane vesicle exosomes for targeted tumor therapy. Biomaterials. 2014;35(7):2383-90.

80. Liang G, Zhu Y, Ali DJ, Tian T, Xu H, Si K, et al. Engineered exosomes for targeted co-delivery of miR-21 inhibitor and chemotherapeutics to reverse drug resistance in colon cancer. J Nanobiotechnology. 2020:18(1):10

81. Hung ME, Leonard JN. Stabilization of exosome-targeting peptides via engineered glycosylation. J Biol Chem. 2015;290(13):8166-72.

82. Ohno S, Takanashi M, Sudo K, Ueda S, Ishikawa A, Matsuyama N, et al. Systemically injected exosomes targeted to EGFR deliver antitumor microRNA to breast cancer cells. Mol Ther. 2013;21(1):185-91.

83. Zhang Y, Luo C-L, He B-C, Zhang J-M, Cheng G, Wu X-H. Exosomes derived from IL-12-anchored renal cancer cells increase induction of specific antitumor response in vitro: a novel vaccine for renal cell carcinoma. Int J Oncol. 2010;36(1):133-40.

84. Rountree RB, Mandl SJ, Nachtwey JM, Dalpozzo K, Do L, Lombardo JR, et al. Exosome targeting of tumor antigens expressed by cancer vaccines can improve antigen immunogenicity and therapeutic efficacy. Can Res. 2011;71(15):5235-44.

85. Kanuma T, Yamamoto T, Kobiyama K, Moriishi E, Masuta Y, Kusakabe T, et al. CD63-mediated antigen delivery into extracellular vesicles via DNA vaccination results in robust CD8 T cell responses. J Immunol. 2017;198(12):4707-15.
86. Salunkhe S, Dheeraj, Basak M, Chitkara D, Mittal A. Surface functionalization of exosomes for target-specific delivery and in vivo imaging \& tracking: strategies and significance. J Control Release. 2020;326:599-614.

87. Jia G, Han Y, An Y, Ding Y, He C, Wang X, et al. NRP-1 targeted and cargo-loaded exosomes facilitate simultaneous imaging and therapy of glioma in vitro and in vivo. Biomaterials. 2018;178:302-16.

88. Tian T, Zhang H-X, He C-P, Fan S, Zhu Y-L, Qi C, et al. Surface functionalized exosomes as targeted drug delivery vehicles for cerebral ischemia therapy. Biomaterials. 2018;150:137-49.

89. Wang J, Li W, Lu Z, Zhang L, Hu Y, Li Q, et al. The use of RGD-engineered exosomes for enhanced targeting ability and synergistic therapy toward angiogenesis. Nanoscale. 2017;9(40):15598-605.

90. Goh WJ, Zou S, Lee CK, Ou Y-H, Wang J-W, Czarny B, et al. EXOPLEXs: chimeric drug delivery platform from the fusion of cell-derived nanovesicles and liposomes. Biomacromol. 2018;19(1):22-30.

91. Piffoux M, Silva AKA, Wilhelm C, Gazeau F, Tareste D. Modification of extracellular vesicles by fusion with liposomes for the design of personalized biogenic drug delivery systems. ACS Nano. 2018;12(7):6830-42.

92. Hoppstadter J, Dembek A, Linnenberger R, Dahlem C, Barghash A, Fecher-Trost $C$, et al. Toll-like receptor 2 release by macrophages: an anti-inflammatory program induced by glucocorticoids and lipopolysaccharide. Front Immunol. 2019;10:1634.

93. Zhou T, Yuan Z, Weng J, Pei D, Du X, He C, et al. Challenges and advances in clinical applications of mesenchymal stromal cells. J Hematol Oncol. 2021;14(1):24.

94. Doeppner TR, Herz J, Görgens A, Schlechter J, Ludwig A-K, Radtke S, et al. Extracellular vesicles improve post-stroke neuroregeneration and prevent postischemic immunosuppression. Stem Cells Transl Med. 2015:4(10):1131-43.

95. Kamerkar S, LeBleu VS, Sugimoto H, Yang S, Ruivo CF, Melo SA, et al. Exosomes facilitate therapeutic targeting of oncogenic KRAS in pancreatic cancer. Nature. 2017;546(7659):498-503.

96. Veerman RE, Güçlüler Akpinar G, Eldh M, Gabrielsson S. Immune cellderived extracellular vesicles-functions and therapeutic applications. Trends Mol Med. 2019;25(5):382-94.

97. Saleem SN, Abdel-Mageed AB. Tumor-derived exosomes in oncogenic reprogramming and cancer progression. Cell Mol Life Sci. 2015;72(1):1-10.

98. Zhu X, Badawi M, Pomeroy S, Sutaria DS, Xie Z, Baek A, et al. Comprehensive toxicity and immunogenicity studies reveal minimal effects in mice following sustained dosing of extracellular vesicles derived from HEK293T cells. J Extracell Vesicles. 2017;6(1):1324730.

99. Shi J, Kantoff PW, Wooster R, Farokhzad OC. Cancer nanomedicine: progress, challenges and opportunities. Nat Rev Cancer. 2017;17(1):20-37.

100. Dabrowska S, Andrzejewska A, Lukomska B, Janowski M. Neuroinflammation as a target for treatment of stroke using mesenchymal stem cells and extracellular vesicles. J Neuroinflammation. 2019;16(1):178

101. Wolfram J, Yang Y, Shen J, Moten A, Chen C, Shen H, et al. The nanoplasma interface: Implications of the protein corona. Colloids Surf B Biointerfaces. 2014:124:17-24.

102. Joo HS, Suh JH, Lee HJ, Bang ES, Lee JM. Current knowledge and future perspectives on mesenchymal stem cell-derived exosomes as a new therapeutic agent. Int J Mol Sci. 2020;21(3):727.

103. O'Brien KP, Khan S, Gilligan KE, Zafar H, Lalor P, Glynn C, et al. Employing mesenchymal stem cells to support tumor-targeted delivery of extracellular vesicle (EV)-encapsulated microRNA-379. Oncogene. 2018;37(16):2137-49.

104. Katakowski M, Buller B, Zheng X, Lu Y, Rogers T, Osobamiro O, et al. Exosomes from marrow stromal cells expressing miR-146b inhibit glioma growth. Cancer Lett. 2013;335(1):201-4.

105. Lang FM, Hossain A, Gumin J, Momin EN, Shimizu Y, Ledbetter D, et al. Mesenchymal stem cells as natural biofactories for exosomes carrying miR-124a in the treatment of gliomas. Neuro Oncol. 2018;20(3):380-90.

106. Wang B, Wu ZH, Lou PY, Chai C, Han SY, Ning JF, et al. Human bone marrowderived mesenchymal stem cell-secreted exosomes overexpressing microRNA-34a ameliorate glioblastoma development via down-regulating MYCN. Cell Oncol (Dordr). 2019;42(6):783-99. 
107. Xu Y, Shen L, Li F, Yang J, Wan X, Ouyang M. microRNA-16-5p-containing exosomes derived from bone marrow-derived mesenchymal stem cells inhibit proliferation, migration, and invasion, while promoting apoptosis of colorectal cancer cells by downregulating ITGA2. J Cell Physiol. 2019;234(11):21380-94.

108. Jiang S, Mo C, Guo S, Zhuang J, Huang B, Mao X. Human bone marrow mesenchymal stem cells-derived microRNA-205-containing exosomes impede the progression of prostate cancer through suppression of RHPN2. J Exp Clin Cancer Res. 2019:38(1):495.

109. Yuan L, Liu Y, Qu Y, Liu L, Li H. Exosomes derived from MicroRNA-148b-3poverexpressing human umbilical cord mesenchymal stem cells restrain breast cancer progression. Front Oncol. 2019;9:1076.

110. Li X, Liu LL, Yao JL, Wang K, Ai H. Human umbilical cord mesenchymal stem cell-derived extracellular vesicles inhibit endometrial cancer cell proliferation and migration through delivery of exogenous miR-302a. Stem Cells Int. 2019;2019:8108576.

111. Wu DM, Wen X, Han XR, Wang S, Wang YJ, Shen M, et al. Bone marrow mesenchymal stem cell-derived exosomal MicroRNA-126-3p inhibits pancreatic cancer development by targeting ADAM9. Mol Ther Nucleic Acids. 2019;16:229-45.

112. Zhang $H$, Wang J, Ren T, Huang $Y$, Liang $X$, Yu Y, et al. Bone marrow mesenchymal stem cell-derived exosomal miR-206 inhibits osteosarcoma progression by targeting TRA2B. Cancer Lett. 2020;490:54-65.

113. Meng Q, Zhang B, Zhang Y, Wang S, Zhu X. Human bone marrow mesenchymal stem cell-derived extracellular vesicles impede the progression of cervical cancer via the miR-144-3p/CEP55 pathway. J Cell Mol Med. 2021;25(4):1867-83

114. Li P, Xin H, Lu L. Extracellular vesicle-encapsulated microRNA-424 exerts inhibitory function in ovarian cancer by targeting MYB. J Transl Med. 2021;19(1):4.

115. Shimbo K, Miyaki S, Ishitobi H, Kato Y, Kubo T, Shimose S, et al. Exosomeformed synthetic microRNA-143 is transferred to osteosarcoma cells and inhibits their migration. Biochem Biophys Res Commun. 2014;445(2):381-7.

116. Ma M, Chen S, Liu Z, Xie H, Deng H, Shang S, et al. miRNA-221 of exosomes originating from bone marrow mesenchymal stem cells promotes oncogenic activity in gastric cancer. Onco Targets Ther. 2017;10:4161-71.

117. Zhang K, Dong C, Chen M, Yang T, Wang X, Gao Y, et al. Extracellular vesiclemediated delivery of miR-101 inhibits lung metastasis in osteosarcoma. Theranostics. 2020;10(1):411-25.

118. NaseriZ, Oskuee RK, Jaafari MR, Forouzandeh MM. Exosome-mediated delivery of functionally active miRNA-142-3p inhibitor reduces tumorigenicity of breast cancer in vitro and in vivo. Int J Nanomed. 2018;13:7727-47.

119. Mendt M, Kamerkar S, Sugimoto H, MCAndrews KM, Wu CC, Gagea M, et al. Generation and testing of clinical-grade exosomes for pancreatic cancer. JCl Insight. 2018;3(8):e99263.

120. Zhou W, Zhou Y, Chen X, Ning T, Chen H, Guo Q, et al. Pancreatic cancertargeting exosomes for enhancing immunotherapy and reprogramming tumor microenvironment. Biomaterials. 2021;268:120546.

121. Altanerova U, Jakubechova J, Benejova K, Priscakova P, Pesta M, Pitule P, et al. Prodrug suicide gene therapy for cancer targeted intracellular by mesenchymal stem cell exosomes. Int J Cancer. 2019;144(4):897-908.

122. Pascucci L, Cocce V, Bonomi A, Ami D, Ceccarelli P, Ciusani E, et al. Paclitaxel is incorporated by mesenchymal stromal cells and released in exosomes that inhibit in vitro tumor growth: a new approach for drug delivery. J Control Release. 2014;192:262-70.

123. Melzer C, Rehn V, Yang Y, Bahre H, von der Ohe J, Hass R. Taxol-loaded MSCderived exosomes provide a therapeutic vehicle to target metastatic breast cancer and other carcinoma cells. Cancers (Basel). 2019;11 (6):798.

124. CocceV, Franze S, Brini AT, Gianni AB, Pascucci L, Ciusani E, et al. In vitro anticancer activity of extracellular vesicles (EVs) secreted by gingival mesenchymal stromal cells primed with paclitaxel. Pharmaceutics. 2019;11(2):61.

125. Bagheri E, Abnous K, Farzad SA, Taghdisi SM, Ramezani M, Alibolandi M. Targeted doxorubicin-loaded mesenchymal stem cells-derived exosomes as a versatile platform for fighting against colorectal cancer. Life Sci. 2020;261:118369.
126. Yuan Z, Kolluri KK, Gowers KH, Janes SM. TRAll delivery by MSC-derived extracellular vesicles is an effective anticancer therapy. J Extracell Vesicles. 2017:6(1):1265291.

127. Zhuang M, Chen X, Du D, Shi J, Deng M, Long Q, et al. SPION decorated exosome delivery of TNF-alpha to cancer cell membranes through magnetism. Nanoscale. 2020;12(1):173-88.

128. Lou G, Chen L, Xia C, Wang W, Qi J, Li A, et al. MiR-199a-modified exosomes from adipose tissue-derived mesenchymal stem cells improve hepatocellular carcinoma chemosensitivity through mTOR pathway. J Exp Clin Cancer Res. 2020;39(1):4.

129. Lou G, Song X, Yang F, Wu S, Wang J, Chen Z, et al. Exosomes derived from miR-122-modified adipose tissue-derived MSCs increase chemosensitivity of hepatocellular carcinoma. J Hematol Oncol. 2015;8:122.

130. Munoz JL, Bliss SA, Greco SJ, Ramkissoon SH, Ligon KL, Rameshwar P. Delivery of functional anti-miR-9 by mesenchymal stem cell-derived exosomes to glioblastoma multiforme cells conferred chemosensitivity. Mol Ther Nucleic Acids. 2013;2:e126.

131. Bliss SA, Sinha G, Sandiford OA, Williams LM, Engelberth DJ, Guiro K, et al. Mesenchymal stem cell-derived exosomes stimulate cycling quiescence and early breast cancer dormancy in bone marrow. Can Res. 2016;76(19):5832-44.

132. Rajendran RL, Paudel S, Gangadaran P, Oh JM, Oh EJ, Hong CM, et al. Extracellular vesicles act as nano-transporters of tyrosine kinase inhibitors to revert iodine avidity in thyroid cancer. Pharmaceutics. 2021;13(2):248.

133. Teng F, Fussenegger $M$. Shedding light on extracellular vesicle biogenesis and bioengineering. Adv Sci (Weinh). 2020;8(1):2003505.

134. Zhang X, Zhang H, Gu J, Zhang J, Shi H, Qian H, et al. Engineered extracellular vesicles for cancer therapy. Adv Mater. 2021;33:e2005709.

135. Clinical Trials. https://www.clinicaltrials.gov/.

136. Jang SC, Kim OY, Yoon CM, Choi DS, Roh TY, Park J, et al. Bioinspired exosome-mimetic nanovesicles for targeted delivery of chemotherapeutics to malignant tumors. ACS Nano. 2013;7(9):7698-710.

137. Jo W, Kim J, Yoon J, Jeong D, Cho S, Jeong H, et al. Large-scale generation of cell-derived nanovesicles. Nanoscale. 2014;6(20):12056-64.

138. LuM, HuangY. Bioinspired exosome-like therapeutics and delivery nanoplatforms. Biomaterials. 2020;242:119925.

139. Antimisiaris SG, Mourtas S, Marazioti A. Exosomes and exosome-inspired vesicles for targeted drug delivery. Pharmaceutics. 2018;10(4):218.

140. Kalimuthu S, Gangadaran P, Rajendran RL, Zhu L, Oh JM, Lee HW, et al. A new approach for loading anticancer drugs into mesenchymal stem cell-derived exosome mimetics for cancer therapy. Front Pharmacol. 2018:9:1116.

141. Zhao Q, Hai B, Zhang X, Xu J, Koehler B, Liu F. Biomimetic nanovesicles made from iPS cell-derived mesenchymal stem cells for targeted therapy of triple-negative breast cancer. Nanomedicine. 2020;24:102146.

142. Zhao Q, Hai B, Kelly J, Wu S, Liu F. Extracellular vesicle mimics made from iPS cell-derived mesenchymal stem cells improve the treatment of metastatic prostate cancer. Stem Cell Res Ther. 2021;12(1):29.

143. Zhao Q, Gregory CA, Lee RH, Reger RL, Qin L, Hai B, et al. MSCs derived from iPSCs with a modified protocol are tumor-tropic but have much less potential to promote tumors than bone marrow MSCs. Proc Natl Acad Sci USA. 2015;112(2):530-5.

144. Sabapathy V, Kumar S. hiPSC-derived iMSCs: NextGen MSCs as an advanced therapeutically active cell resource for regenerative medicine. J Cell Mol Med. 2016;20(8):1571-88.

145. Jungbluth P, Spitzhorn LS, Grassmann J, Tanner S, Latz D, Rahman MS, et al. Human iPSC-derived iMSCs improve bone regeneration in mini-pigs. Bone research. 2019;7:32.

146. Crescitelli R, Lasser C, Lotvall J. Isolation and characterization of extracellular vesicle subpopulations from tissues. Nat Protoc. 2021;16:1548-80.

\section{Publisher's Note}

Springer Nature remains neutral with regard to jurisdictional claims in published maps and institutional affiliations. 